\title{
Effects of galU Mutation on Pseudomonas syringae-Plant Interactions
}

\author{
Wen-Ling Deng, ${ }^{1}$ Yuan-Chun Lin, ${ }^{2}$ Rong-Hwa Lin, ${ }^{3,4}$ Chia-Fong Wei, ${ }^{2}$ Yi-Chiao Huang, ${ }^{2}$ Hwei-Ling Peng, ${ }^{4}$ \\ and Hsiou-Chen Huang ${ }^{2}$
}

${ }^{1}$ Department of Plant Pathology, ${ }^{2}$ Graduate Institute of Biotechnology, and ${ }^{3}$ Biotechnology Center, National Chung Hsing University, Taichung, 40224, Taiwan; ${ }^{4}$ Department of Biological Science and Technology, National Chiao Tung University, Hsin Chiu 30050, Taiwan

Submitted 3 December 2009. Accepted 3 May 2010.

\begin{abstract}
Bacterial galU coding for a uridine diphosphate-glucose pyrophosphorylase plays an important role in carbohydrates biosynthesis, including synthesis of lipopolysaccharides (LPS), membrane-derived oligosaccharides, and capsular polysaccharides. In this study, we characterized the galU mutant of Pseudomonas syringae pv. syringae 61 (Psy61), a necrotizing plant pathogen whose pathogenicity depends on a functional type III secretion system (T3SS), and showed that the Psy61 galU mutant had reduced biofilm formation ability, was nonmotile, and had an assembled T3SS structure but failed to elicit hypersensitive response in resistant plants and necrotic lesions in susceptible plants. Moreover, the defective LPS and other pathogenassociated molecular patterns (PAMPs) on the surface of the Psy61 galU mutant were capable of inducing PAMPtriggered immunity, which severely compromised the ability of the Psy61 galU mutant to survive in planta. Our results demonstrated that the complete LPS protected plant-pathogenic bacteria from host innate immunity, similar to what was found in animal pathogens, prior to the translocation of T3S effectors and bacterial multiplication.
\end{abstract}

Phytopathogenic Pseudomonas syringae pv. syringae 61 (Psy61) was previously characterized as a potent hypersensitive response (HR)-eliciting bacterium on tobacco, whose HR-eliciting activity depends on a functional type III secretion system (T3SS) and an array of effectors that were encoded by the $h r p / h r c / h o p$ genes (Huang et al. 1995; Collmer et al. 2000). Mutations in genes coding for the T3SS led to the incapability of eliciting $\mathrm{HR}$ in resistant plants and multiplication in susceptible plants, whereas T3S effectors (e.g., AvrPtoB) (Abramovitch et al. 2003), are known virulence proteins that are involved in promoting parasitism by various mechanisms (Mudgett 2005). Other virulence-associated genes involved in the biosynthesis of exopolysaccharides (EPS), extracellular enzymes, and toxins have differential contributions to the infectivity on susceptible plants without compromising their HR-eliciting ability on resistant plants (Beattie and Lindow

W.-L. Deng and Y.-C. Lin contributed equally to this work.

Corresponding author: H.-C. Huang; Telephone: +886-4-22852155; Fax: +886-4-22853527; E-mail: hchuang@dragon.nchu.edu.tw

Nucleotide sequence data reported is available in the GenBank database under the accession number U03751.

* The $\boldsymbol{e}$-Xtra logo stands for "electronic extra" and indicates that Figures 1,6 , and 8 appear in color online.
1994). The HR, also known as gene-for-gene defense response or effector-triggered immunity (ETI) (Jones and Dangl 2006), is achieved by successful recognition of the T3S effectors by various plant resistance $(\mathrm{R})$ proteins. Aside from ETI, plant cells recognize pathogen-associated or microbe-associated molecular patterns (PAMPs or MAMPs) by pattern-recognition receptors to launch a quick but less specific PAMP-triggered immunity (PTI) that can restrict bacterial growth (He et al. 2007; Schwessinger and Zipfel 2008). The PTI occurred early upon the invasion of both pathogenic and nonpathogenic bacteria; therefore, it becomes the first active defense encountered by microbial invaders. Successful pathogens must overcome the PTI before they can grow in planta. The bacterial cell wall serves as a shielding armor to protect bacteria against the early defense prior to the expression and translocation of T3S effectors-for example, AvrPto (Hauck et al. 2003) and HopPtoM (DebRoy et al. 2004) —into plant cells to actively suppress the PTI.

In gram-negative bacteria, such as Psy61 used in this study, the cell wall is composed of peptidoglycan and an outer membrane in which lipopolysaccharide (LPS) is a major component. LPS is a tripartite molecule consisting of lipid A, core oligosaccharides, and $\mathrm{O}$-antigen. The $\mathrm{O}$-antigen plays an important role as a virulence factor in many gram-negative, animal-pathogenic bacteria (Finlay and McFadden 2006), whereas the lipid A moiety, recognized by Toll-like receptor (TLR) proteins, induces innate and acquired immunity in mammalian systems (Miller et al. 2005). In plant systems, the oligosaccharide moieties of LPS induce localized defense-related responses that can be readily detected by the suppression of ETI elicited by subsequent pathogen inoculation (Newman et al. 2001; Klement et al. 2003). Similar to the mammalian innate immunity, the perception of bacterial LPS in Arabidopsis thaliana induces the expression of nitric oxide (NO) synthase and the accumulation of $\mathrm{NO}$, leading to the expression of defenserelated genes and accounting for the resistance to pathogenic bacteria (Zeidler et al. 2004). Purified LPS also induces defense responses associated with programmed cell death in rice (Desaki et al. 2006) and systemic resistance in radish (Leeman et al. 1995), potato (Reitz et al. 2000), and A. thaliana (Van Wees et al. 1997), although the critical structures of LPS recognized by individual plant species remain to be elucidated.

The aim of this work was to study the fate of LPS-defective Psy61 in planta by creating a marker-exchanged mutation in galU. The galU codes for a uridine diphosphate (UDP)-glucose pyrophosphorylase with a well-defined role in the LPS biosynthesis by synthesizing UDP-glucose (UDP-Glc) from glucose 1-phosphate and UTP (Schulman and Kennedy 1977). 
The galU mutants of animal-pathogenic bacteria-for example, Klebsiella pneumoniae (Chang et al. 1996), P. aeruginosa (Priebe et al. 2004), and Shigella flexneri (Sandlin et al. 1995) produce an altered LPS structure lacking all sugars beyond the heptose residues, cause a loss of flagellar motility, reduce biofilm formation, and attenuate virulence for host infection. The galU mutation also affects the secretion of Escherichia coli $\alpha$-haemolysin and Dickeya dadantii (previously known as Erwinia chrysanthemi) proteases via the type I secretion system (T1SS) (Wandersman and Letoffe 1993) and the correct trafficking of S. flexneri IcsA on the cell surface (Sandlin et al. 1995). Nevertheless, the truncated LPS of the $S$. flexneri galU mutant does not appear to interfere with the formation and function of the T3SS, which was supported by the abundance of T3SS structure emerging from the outer membrane and the potential of bacterial invasion into epithelial cells (West et al. 2005). Based on the traits of the Psy61 galU mutant in this study, we reported that the physical barrier of LPS is critical for protecting plantassociated bacteria from PTI. The incomplete LPS of the Psy61 galU mutant lacking $\mathrm{O}$-antigen and an outer oligosaccharide core can still mediate the interaction between the bacteria and plant cells to induce PTI which, consequently, arrests bacterial growth in the initial phase of infections before the bacteria translocate T3S effectors into plant cells. As a result, the LPS-deficient mutant cannot survive in susceptible plants or elicit the HR in resistant plants even though it is capable of assembling the T3SS.

\section{RESULTS}

Cloning and sequencing

of a Psy61 genomic region harboring galU.

Escherichia coli FF4001 (Brede et al. 1991) harboring Psy61-derived genomic library plasmids was grown on MacConkey agar plates supplemented with $0.2 \%$ galactose, and the transformants that could grow and form red colonies on the plates were selected. One recombinant clone, pNCHU467, was chosen for further characterization. Sequence analysis revealed that pNCHU467 has an insert of 2,742 bp harboring complete galU and gor genes coding for a putative UDP-Glc pyrophosphorylase and glutathione reductase, respectively (Fig. 1A). The nucleotide sequences of Psy61 galU share $80 \%$ identity with the $P$. aeruginosa ATCC10145 galU gene (GenBank accession no. U03751) that has been biochemically characterized to encode a functional UDP-Glc pyrophosphoylase (Chang et al. 1999). In addition, a number of putative galU sequences of Pseudomonas spp. were identified from the GenBank database that display high similarities, ranging from 77 to $94 \%$, to the Psy61 galU. Comparison of their deduced amino acid sequences shows some substitutions between residues 143 and 153, whereas the rest of the amino acid sequences are identical to one another.

Biochemical characterization of Psy61 galU mutant.

Using the cloned plasmid pNCHU467, a deletion in Psy61 galU was generated by marker-exchange strategy. The relevant
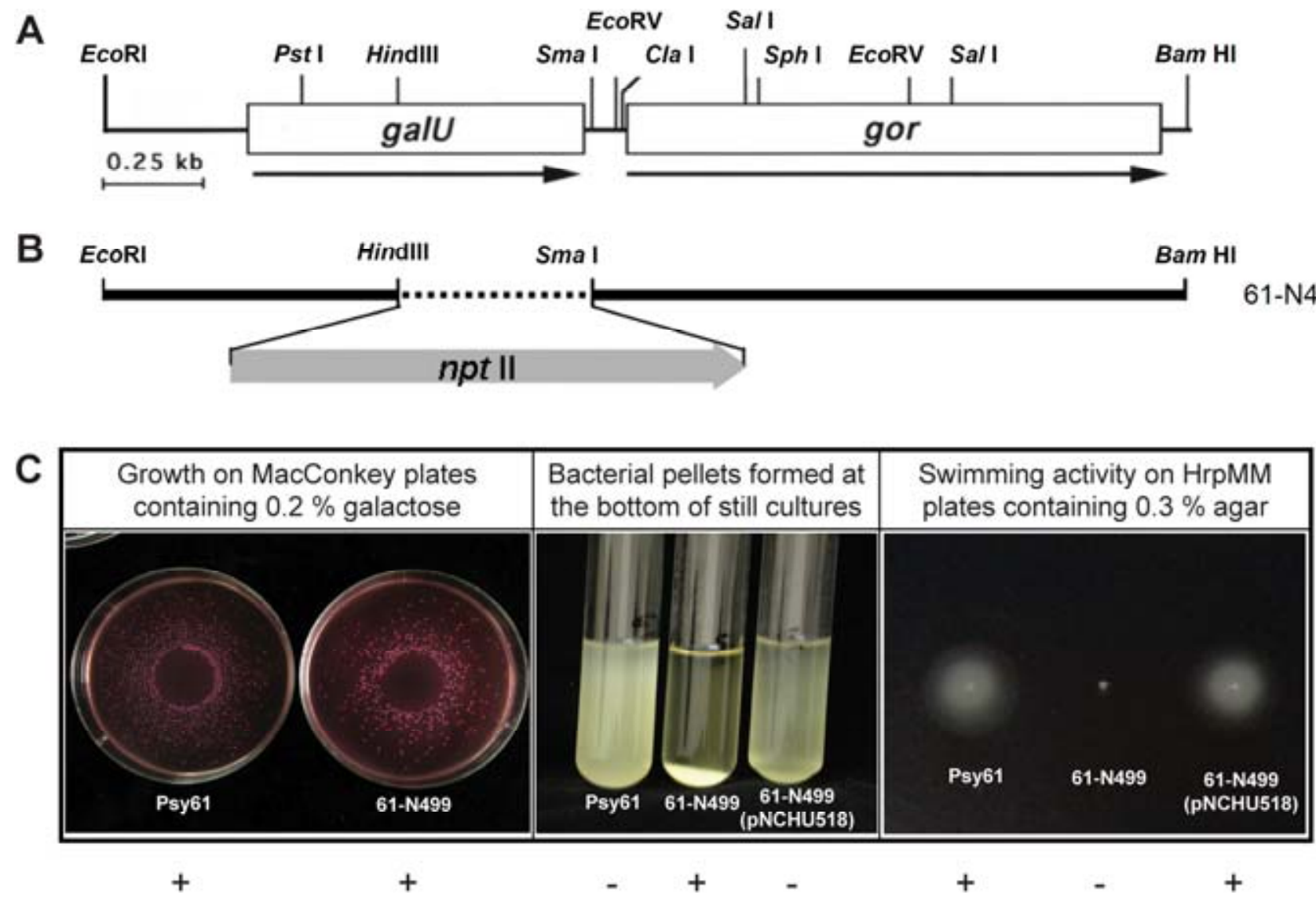

Fig. 1. Construction and phenotypes of the galU mutation in Pseudomonas syringae pv. syringae 61 (Psy61). A, Schematic presentation of the cloned 2.7-kb DNA fragment containing galU and gor genes. Coding regions are shown in open boxes, and arrowed lines indicate the direction of transcription. B, Gray arrow in the mutant construction denotes the terminator-lacking nptII cassette and its transcriptional direction, and dashed line represents internal deletion of galU coding region that is replaced by the nptII cassette. C, Phenotypes of Psy61 (wild type), 61-N499 (galU mutant), and 61-N499 (pNCHU518) (complementing strain) on different medium. Left panel: galactose sensitivity test on MacConkey agar plates supplemented with $0.2 \%$ galactose, "+" reaction indicates bacterial growth. The colony-forming and growing phenotypes of the complementing strain are similar to 61-N499 (data not shown). Middle panel: sedimentation test in King's B broth; "+" and "-” reaction indicates bacterial sedimentation and no sedimentation in still-liquid cultures, respectively. Right panel: bacterial motility on Hrp-derepressing medium (HrpMM) containing 0.3\% agar; "+" and "-" represent bacterial swimming and no-swimming phenotypes, respectively. 
gene organization of the resultant mutant strain 61-N499 (Fig. 1B) was confirmed by Southern hybridization and polymerase chain reaction (PCR) (data not shown). The galU mutant 61N499 was characterized for its growth on MacConkey agar plates containing $0.2 \%$ galactose, bacterial sedimentation in a still-liquid culture, and motility on $0.3 \%$ HrpMM agar medium. The results showed that $61-\mathrm{N} 499$ is drastically different
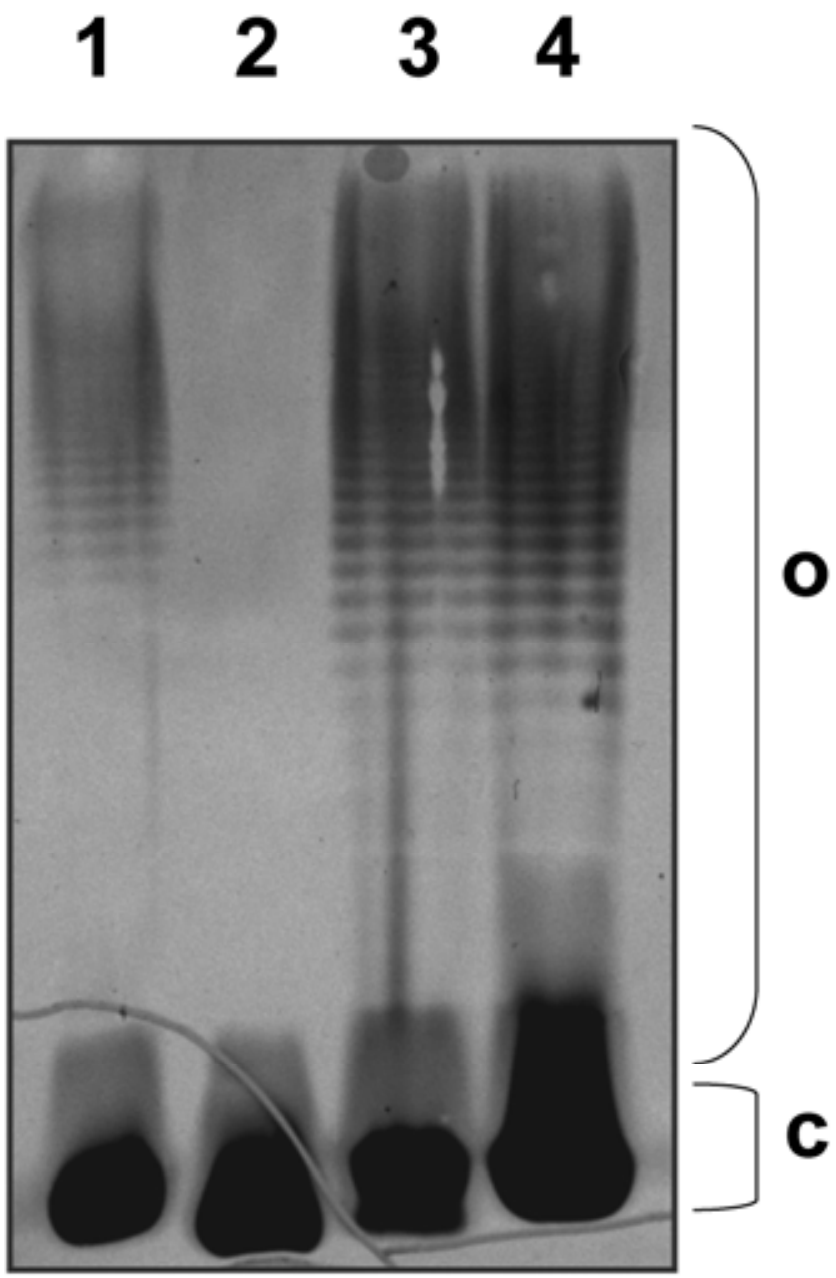

Fig. 2. Sodium dodecyl sulfate polyacrylamide gel electrophoresis (SDSPAGE) (12\% acrylamide) analysis of lipopolysaccharide (LPS) from Pseudomonas syringae pv. syringae 61 (Psy61) and its derivatives. Lane 1, type III secretion system-defective mutant 61-N393 ( $h r c C$ mutant); lane 2, 61N499 (galU mutant); lane 3, 61-N499 (pNCHU518) (complementing strain); lane 4, wild-type Psy61. LPS was extracted by phenol-water method, separated by SDS-PAGE, and stained by silver nitrate. $\mathrm{O}=\mathrm{O}$ antigen; $\mathrm{C}=$ LPS core. from the wild-type Psy61 in all assays, except that it can grow as well as the wild type on MacConkey plate supplemented with $0.2 \%$ galactose (Fig. 1C). LPS prepared from 61-N499 was devoid of $\mathrm{O}$-antigen, and its LPS core migrated slightly faster than that of the wild-type strain (Fig. 2). The 61-N499 had no detectable UDP-Glc pyrophosphorylase activity $(<0.1$ unit) compared with the specific activity of 35.13 units for Psy61 (Table 1). 61-N499 grown in King's B (KB) broth had reduced capability of forming biofilms on plastic surfaces (determined by crystal violet staining, as described below). The stained biofilms at 595-nm absorbance were $0.114 \pm 0.009$ and $0.332 \pm 0.045$ for 61-N499 and Psy61, respectively (Table 1). In addition, $\mathrm{H}_{2} \mathrm{O}_{2}$ sensitivity assays showed the diameters of the inhibition zone on KB agar plates were $17.5 \pm 0.299$ for Psy61 and $22.63 \pm 0.674$ for $61-N 499$, indicating that $61-N 499$ is more sensitive to hydrogen peroxide than the wild-type Psy61 (Table 1). The 61-N499 mutant phenotypes could be rescued by introducing the plasmid pNCHU518 containing the complete $g a l U$ coding region, indicating that a single mutation in galU leads to multiple alterations in the biological activities of Psy61 (data not shown). The results are in agreement with previously characterized galU mutations in other gram-negative bacteria, except for the colony forming capability on MacConkey agar containing $0.2 \%$ galactose, on which the growth of enteric bacteria galU mutants is inhibited (Brede et al. 1991).

\section{Microscopic observation of flagella on bacterial surface.}

The motility assay in Figure 1C showed that the Psy61 galU mutant has marked reduction in motility, which prompted us to examine the flagellar biogenesis in the galU mutant. The flagellar filaments were collected by shearing flagella off bacterial surfaces, denatured in $2 \times$ sodium dodecyl sulfate polyacrylamide gel electrophoresis (SDS-PAGE) sample buffer, and detected by immunoblotting with FliC antiserum. The result showed that the amount of flagellin collected from the surface of the Psy61 galU mutant was much lower than that in the wild-type Psy61 (Fig. 3A, upper left and central panels); nevertheless, the flagellin of the galU mutant was as glycosylated as that of its wild type (Fig. 3A, upper right panel). Taguchi and associates (2008) showed that the glycosylation of flagellin stabilizes flagellar filament structure and is required for swarming and adhesion abilities. Mutation of galU in Psy61 does not affect flagellin glycosylation (Fig. 3A), indicating that the reduced number of flagella on the surface of 61-N499 is not due to the formation of unstable, nonglycosylated flagellar filament. Concerned with the low recovery of flagellar filaments, we monitored flagellin synthesis in Psy61 and 61-N499 by simultaneously resolving equal amount of total proteins prepared from cultured bacteria (TF fractions) in 12\% SDS PAGE for Coomassie blue staining (data not shown) and immu-

Table 1. Phenotypic characterization of Pseudomonas syringae pv. syringae 61 (Psy61) and its derivative galU mutant ${ }^{\mathrm{a}}$

\begin{tabular}{lcc}
\hline Phenotypes, strains & Psy61 & galU mutant \\
\hline${\text { Biofilm formation }\left(\mathrm{OD}_{595} \text { absorbance) }\right.}^{\mathrm{b}}$ & $0.332 \pm 0.045$ & $0.114 \pm 0.009$ \\
UDP-Glc pyrophosphorylase activity $^{\mathrm{c}}$ & 35.13 & $<0.1$ (ND) \\
Bacteria with surface flagella (\%) $^{\mathrm{d}}$ & $22.65 \pm 0.095$ & $2.27 \pm 0.032$ \\
$\mathrm{H}_{2} \mathrm{O}_{2}$ sensitivity $(\mathrm{mm})^{\mathrm{e}}$ & $17.50 \pm 0.299$ & $22.63 \pm 0.674$ \\
\hline
\end{tabular}

${ }^{a}$ All values listed in this table are significantly different based on Duncan's analysis.

${ }^{\mathrm{b}}$ Bacteria were cultured in King's B (KB) broth for $70 \mathrm{~h}$ before assay for biofilm formation at and optical density at $595 \mathrm{~nm}\left(\mathrm{OD}_{595}\right)$ absorbance $(\mathrm{means} \pm$ standard deviation $[\mathrm{SD}]$ of three replications).

${ }^{c}$ Specific units of uridine diphosphate-glucose (UDP-Glc) pyrophosphorylase was determined by the synthesis of nanomoles NADPH per minute per milligram of total proteins. ND, no detectable activity.

${ }^{\mathrm{d}}$ Percentage of surface flagella (means \pm SD of nine fields) was calculated from the number of bacteria bearing intact flagella observed by transmission electron microscopy.

${ }^{\text {e }} \mathrm{H}_{2} \mathrm{O}_{2}$ sensitivity, shown in millimeters of diameter (means \pm SD of three replications), was assayed by disk diffusion test using 6-mm-diameter paper disk containing $0.1 \%$ ( $\mathrm{vol} / \mathrm{vol}$ ) hydrogen peroxide on $\mathrm{KB}$ agar. 
nodetecting with FliC antiserum (Fig. 3A, bottom panel), and the immunoblot revealed that the amount of flagellins in the TF fractions of both bacteria was equal, indicating that the loss of galU does not affect flagellin synthesis, either. Furthermore, bacterial flagellation was directly observed by transmission electron microscopy (TEM), and the percentage of flagellated bacteria was calculated using the total number of bacteria seen in at least nine randomly selected fields. The percentage of flagellated bacteria was greatly reduced in the galU mutant 61 N499 $(2.27 \pm 0.032 \%)$ compared with $22.65 \pm 0.095 \%$ in Psy61 (Table 1). Two representative micrographs were shown in Figure 3B, depicting flagellated bacteria of Psy61 (Fig. 3B, top panel) and the galU mutant 61-N499 (Fig. 3B, bottom panel).

\section{Mutation in galU of Psy61 affects HR elicitation and bacterial survival in tobacco leaves.}

To test whether the galU mutation has altered the ability of Psy61 to elicit an HR, the galU mutant 61-N499 and its complementing strain 61-N499 (pNCHU518) were individually infiltrated into tobacco leaves at a concentration of $10^{8} \mathrm{CFU} / \mathrm{ml}$, and the HR was recorded at $24 \mathrm{~h}$ postinfiltration (hpi). 61-N499 has lost its HR-eliciting activity (Fig. 4A), which can be restored by the heterologous expression of galU harbored in pNCHU518. The null response was further confirmed by staining the infiltrated leaf panels with Evans blue to show that there were only a few dead cells in the 61-N499-infiltrated area at 2 days postinoculation (dpi) (Fig. 4B, second panel from the left), whereas the wild-type Psy61 and the complementing strain 61N499 (pNCHU518) caused massive destruction of tobacco parenchyma cells at $1 \mathrm{dpi}$ (Fig. 4B, first and third panels from the left). The number of dead cells elicited by the galU mutant 61-N499 was not increased with prolonged inoculation time (6 dpi), demonstrating that the reduction of the HR-eliciting abil- ity of the galU mutant could not be restored at a later time. Moreover, the kinetics of bacterial survival in tobacco leaves differed greatly between wild-type Psy61 and galU mutant 61N499 (Fig. 5). Bacteria were infiltrated at concentrations of approximately $10^{8}$ (Fig. 5A) and $10^{5}$ (Fig. 5B) CFU/ml, respectively, and leaf disks were harvested at $0,2,4,6,8,12,24$, 45, and 72 hpi for bacterial enumeration. For Psy61, the leaf panels infiltrated with bacteria of $10^{8}$ or $10^{5} \mathrm{CFU} / \mathrm{ml}$ developed confluent necrosis at 12 to $16 \mathrm{hpi}$ or no discernible phenotype to sporadic necrosis at 24 to $36 \mathrm{hpi}$, respectively, whereas there was no detectable phenotype in the leaves infiltrated with 61-N499 at the two bacterial densities. The population of galU mutant 61-N499 in tobacco leaves declined rapidly after infiltration at both inoculation concentrations, showing that the reduced HR-eliciting ability of galU mutant 61-N499 does not enhance its survival in nonhost tobacco plants.

\section{Mutation in galU of Psy61 reduces \\ bacterial multiplication in susceptible bean plants.}

The multiplication of galU mutant 61-N499 in susceptible hosts was assessed by infiltrating bacteria at both low $\left(10^{5}\right.$ $\mathrm{CFU} / \mathrm{ml})$ and high $\left(10^{8} \mathrm{CFU} / \mathrm{ml}\right)$ concentrations of inocula into bean leaves. Although Psy61 is not strongly virulent to bean, it is the only known plant that is susceptible to Psy61 and has been used previously for testing Psy61 multiplication in planta (Deng et al. 1998). At the initial inoculum of $10^{5} \mathrm{CFU} / \mathrm{ml}$ (Fig. $6 \mathrm{~A}$, right panel), both wild-type Psy61 and the galU mutant 61-N499 grew with similar kinetics during the assay period, except the initial population of the galU mutant was greatly reduced immediately after infiltration, which was evident by the large deviations of bacterial numbers harvested at 0 dpi (leaf disks were collected approximately 2 hpi and ground immediately for enumeration). Similar reduction of the initial bacterial
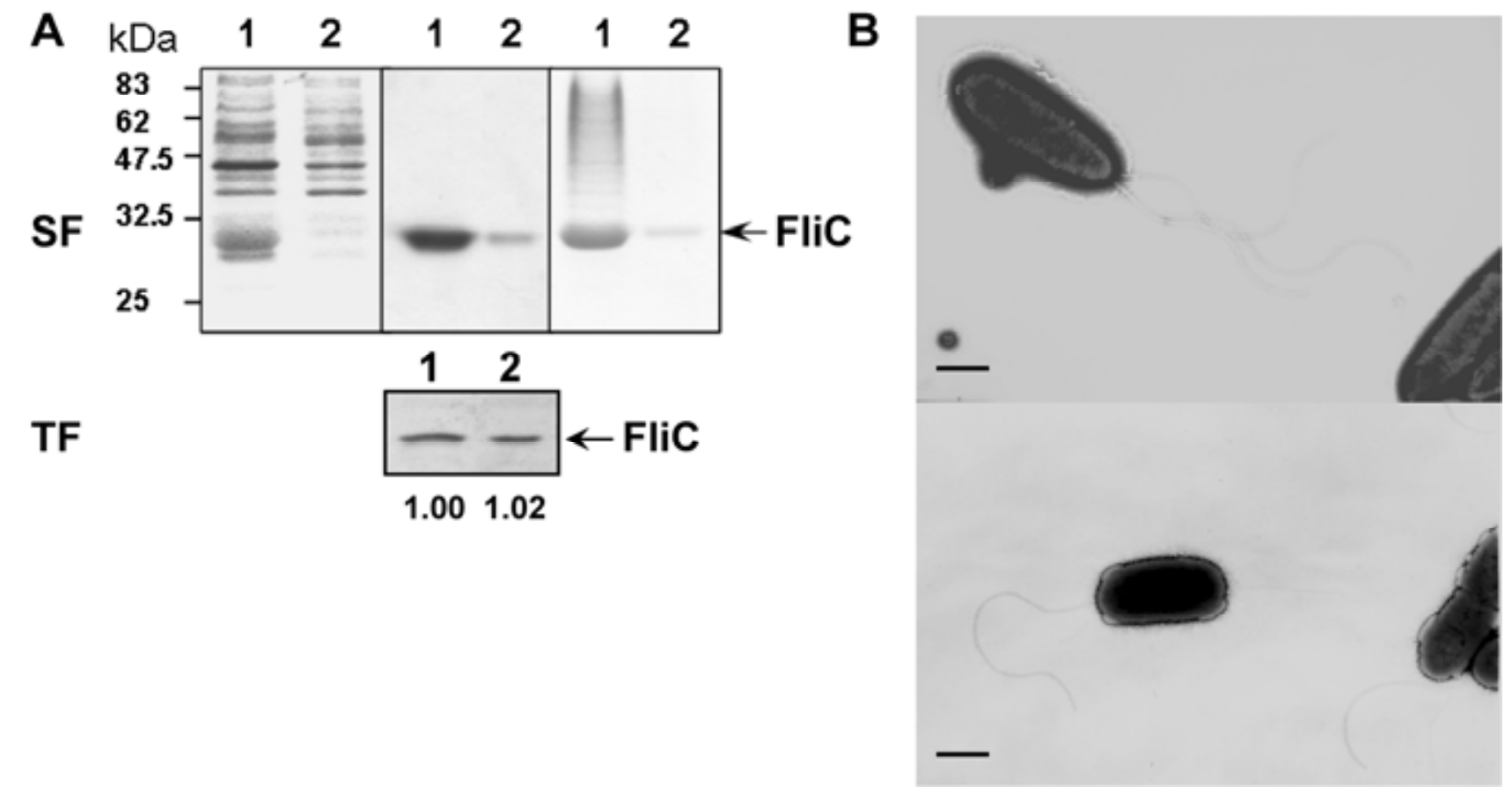

Fig. 3. Purification and detection of flagella from Pseudomonas syringae pv. syringae 61 (Psy61) and its galU mutant 61-N499. A, 12\%-Sodium dodecyl sulfate polyacrylamide gel electrophoresis (SDS-PAGE) resolution and immunodetection of flagellins collected from 24-h HrpMM-cultured bacteria. The upper three panels show the analyses of electrophoretic, denatured sedimented flagella (SF) fractions by staining with Coomassie brilliant blue (upper left panel), probing with FliC antiserum (upper central panel), and staining with GelCode glycoprotein staining kit (upper right panel). The bottom panel shows the Western blot analysis of the total flagellins (TF) that were collected from 24-h HrpMM-grown bacterial suspension and probed with FliC antiserum. The relative concentration of antiserum-bound flagellins is quantified by simultaneously staining an SDS-PAGE gel with Coomassie blue to ensure that each lane contains an equal amount of total proteins prior to immunoblotting, and the banding signals of the antiserum-bound FliC were determined by a densitometer (LAS-4000mini; FUJIFILM Co., Tokyo). Lane 1, Psy61 and lane 2, 61-N499. B, Electron micrographs of Psy61 (top panel) and its galU mutant 61-N499 (bottom panel). Bar $=1 \mu \mathrm{m}$. 
population was observed when bacteria were inoculated at $10^{8}$ CFU/ml (Fig. 6A, left panel). Both wild-type Psy61 and galU mutant 61-N499 reached the highest population at 3 dpi at the two inoculation concentrations, and the population of Psy61 exceeded that of galU mutant by at least four orders of magnitude. Moreover, the Psy61-inoculated leaves started to develop necrotic lesions at $4 \mathrm{dpi}$, whereas the galU mutant failed to elicit any symptom in an assay period of 21 days (data not shown). The pathogenicity of the galU mutant was also tested on bean pods by toothpick pricking inoculation. No symptom development was observed in the galU mutant 61-N499-inoculated pods at 7 dpi (Fig. 6B).

\section{Mutation in galU of Psy61 does not eliminate the capability} of its T3SS to secrete outer proteins into bacterial milieu.

The observation that the galU mutant 61-N499 failed to elicit the HR on tobacco or cause disease on bean led us to examine the function of T3SS by immunodetecting the secretion of T3S substrates HrpZ1 and HopA1. Induced cultures were separated into supernatants (S) and cell pellets (C) by highspeed centrifugation at $15,000 \times g$ to obtain secreted and cytoplasmic proteins, respectively. In contrast to the $h r c C$ mutation (61-N393), the galU mutation did not affect the secretion of HrpZ1 and HopA1-Cya fusion protein, as clearly shown in the immunoblots probed with antibodies against HrpZ1 and Cya (Fig. 7). The result indicates that the galU mutant has a functional T3SS to secrete HrpZ1 and HopA1-Cya into the bacterial milieu.

\section{Psy61 galU mutant induces PTI.}

The HR inhibition test and callose deposition assay were performed to test the capability of the galU mutant possessing incomplete LPS structure on eliciting plant innate immunity. The levels of the HR inhibition were recorded at 24 to 36 hpi using the following scale: 4 , complete inhibition of the HR; 3 , HR developed on approximately $25 \%$ of the co-injected area; 2, HR developed on approximately $50 \%$ of the co-injected area; 1 , HR developed on approximately $75 \%$ of the co-injected area;

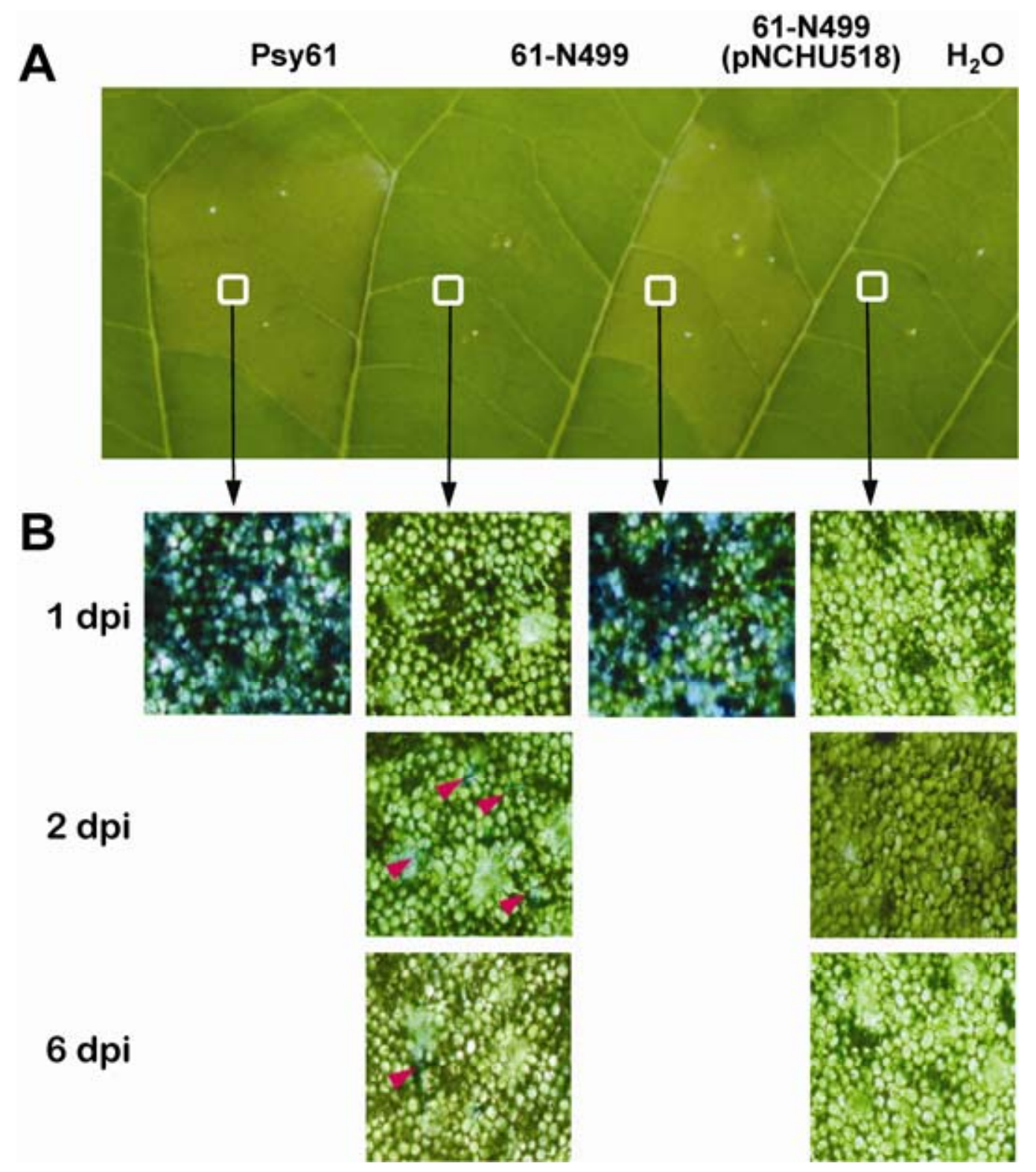

Fig. 4. Development of hypersensitive response (HR) on tobacco leaves. A, HR of tobacco induced by Pseudomonas syringae pv. syringae 61 (Psy61) (wild type), 61-N499 (galU mutant), and 61-N499 (pNCHU518) (complementing strain) at an inoculum of $10^{8} \mathrm{CFU} / \mathrm{ml}$. The inoculated leaf was photographed $24 \mathrm{~h}$ after infiltration. B, Microscopic observations of the inoculated leaf stained with Evans blue at 1, 2, and 6 days postinoculation (dpi). White square boxes indicate the area of microscopic observation, and pink arrowheads indicate compromised plant cells stained by Evans blue. 
and 0 , no inhibition of the HR. Inoculation of fully expanded tobacco leaves with Psy61 at $10^{7} \mathrm{CFU} / \mathrm{ml}$ led to confluent cellular collapse of the HR within $24 \mathrm{~h}$, which was prevented by preinoculation of the tobacco leaves with serially diluted bacteria, including heat-killed Psy61, T3SS-deficient $h r c C$ mutant 61-N393 (Deng et al. 1998), and the galU mutant 61-N499, at $10^{8}, 10^{7}$, and $10^{6} \mathrm{CFU} / \mathrm{ml} 8 \mathrm{~h}$ prior to challenging inoculation (Table 2). The result indicates that the LPS-defective galU mutant can elicit plant innate immunity, although at a moderate level in comparison with the $h r c C$ mutant. The HR inhibition phenotype is positively correlated with the concentrations of pretreated bacteria. The leaf segments where the galU mutant and the challenging Psy61 were inoculated started to show chlorosis at $1 \mathrm{dpi}$ and became necrotic at 2 to $3 \mathrm{dpi}$ (data not shown), indicating that the HR inhibition was temporary. The experiment was repeated twice with similar results. In addition, the HR inhibition phenotype was very pronounced when the bacteria were co-inoculated in young leaves (data not shown), an observation similar to the reported case in which the intensity of PTI induced by general bacterial elicitors was high in young leaves and at high temperature $\left(30^{\circ} \mathrm{C}\right)$ (Ott et al. 2006). Because PTI could also lead to the deposition of callose, callose deposits in leaves of Nicotiana benthamiana were analyzed as described below. After inoculation with the galU mutant, $N$. benthamiana leaves exhibited characteristic callose depositions on the cell wall (Fig. 8), and the numbers of callose deposits induced by galU mutant and $h r c C$ mutant were similar. Taken together, the results indicate that the LPS-defective galU mutant, similar to the LPS-intact $h r c C$ mutant, can induce PTI in tobacco leaves.

\section{DISCUSSION}

In this study, we characterized the biological activities of the Psy61 galU mutant and found that it cannot grow in susceptible plants, nor can it elicit the HR in resistant plants even though it has a complete set of T3SS and effector genes. We hypothesize that the null plant responses elicited by the Psy61
galU mutant might be due to the loss of intact LPS as a protective structure against plant defenses. The hypothesis was tested by bacterial sensitivity to $\mathrm{H}_{2} \mathrm{O}_{2}$ and growth kinetics in plants. Our results showed that i) the Psy61 galU mutant was more sensitive to $\mathrm{H}_{2} \mathrm{O}_{2}$ than the wild type, ii) its survival was reduced immediately after infiltration in both susceptible and resistant plants, and iii) the population of the galU mutant declined more rapidly when a higher bacterial inoculum (i.e., $10^{8}$ versus $10^{5} \mathrm{CFU} / \mathrm{ml}$ ) was injected into the apoplast. All the mutant phenotypes can be fully restored, except for bacterial survival in plants, by heterologous expression of the wild-type galU gene from the $\mathrm{P}_{\text {lac }}$ promoter residing in pRK415, indicating that the multiple defects resulted from a single mutation in the galU gene. The partial complementation of bacterial survival in plants is probably due to the instability of pRK415 when plasmid-harbored strains were grown under no-tetracyclineselection conditions (Keen et al. 1988) (i.e., in the apoplast of plants). Knowing that LPS-induced PTI exhibits callose deposition and prevents the HR elicited by a subsequent inoculation of incompatible phytopathogens (Dow et al. 2000; Newman et al. 2001), tobacco leaves infiltrated with the Psy61 galU mutant were subjected to aniline blue staining and the HR inhibition assay. Our results showed that the LPS-defective galU mutant could induce callose deposition and suppress the HR at the levels comparable with those elicited by the LPS-intact strains (e.g., the heat-killed Psy61 and $h r c C$ mutant), indicating that the truncated LPS on the surface of the Psy61 galU mutant can still induce PTI.

The growth of galU mutants of enteric bacteria (e.g., E. coli and Pectobacterium carotovorum subsp. carotovorum, previously known as Erwinia carotovora subsp. carotovora) in galactose-containing medium was inhibited due to the accumulation of toxic galactose intermediates (Brede et al. 1991), and the toxic effect rendered $P$. carotovorum subsp. carotovorum unable to cause potato tuber decay (Jayaswal et al. 1985). In this work, we showed that the Psy61 galU mutant had no detectable UDP-Glc pyrophosphorylase activity but was able to grow on MacConkey agar plates supplemented

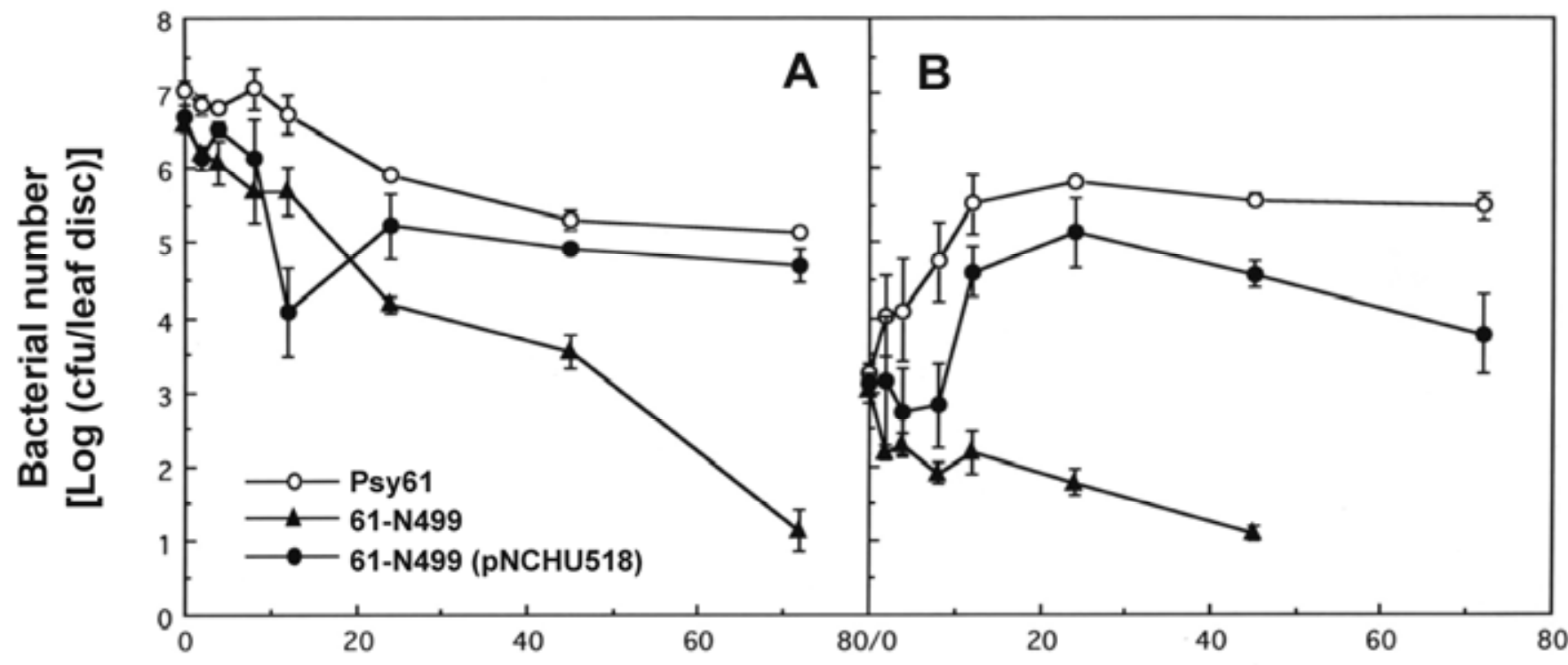

\section{Hours postinoculation}

Fig. 5. Bacterial growth kinetics of Pseudomonas syringae pv. syringae 61 (Psy61), 61-N499 (galU mutant), and 61-N499 (pNCHU518) (complementing strain) in tobacco. Tobacco leaves were syringe-infiltrated with bacteria at $\mathbf{A}, 10^{8}$ and $\mathbf{B}, 10^{5} \mathrm{CFU} / \mathrm{ml}$. Leaf disks were harvested by a cork borer $($ diameter $=$ $6 \mathrm{~mm}$ ), ground in $10 \mathrm{mM} \mathrm{MgCl} 2$ buffer, and spread onto King's B plates supplemented with appropriate antibiotics. Symbols represent the mean of three replications and vertical lines indicate standard deviations. 
with $0.2 \%$ galactose (Fig. 1C). Moreover, a Biolog microtiter plate assay showed that the carbon source utilization pattern of the galU mutant is identical to that of wild-type Psy61 (data not shown). Therefore, we ruled out the possibility that the nonpathogenic phenotypes of Psy61 galU mutant in planta resulted from the lack of enzymatic activities in metabolizing carbohydrates. The lack of growth inhibition by galactose intermediates was also reported in the Pseudomonas aeruginosa galU mutant (Chang et al. 1999), suggesting that there is a GalU-independent pathway for galactose metabolism in Pseudomonas spp.

LPS is known to induce defense responses in both mammals and plants. LPS recognition by a receptor complex of TLR4, MD2, and CD14 activates innate immunity in mammalian systems, leading to cytokine production and activation of antigenpresenting cells (Miller et al. 2005). In plant systems, LPS treatment also induces various defense-related responses, including the production of reactive oxygen species (ROS), the deposition of callose-rich papillae on cell walls (Brown et al. 1995), the expression of NO synthase and pathogenesis-related proteins (Newman et al. 2002; Zeidler et al. 2004; Silipo et al.
2005), the induction of systemic resistance in some plant species (Mishina and Zeier 2007), and the activation of programmed cell death in various plant species (Dow et al. 2000; Desaki et al. 2006). Herein, the question regarding the critical structures of LPS responsible for inducing plant defense responses remains to be elucidated. In previously studied LPStriggered plant innate immunity (PTI), Newman and associates (1997) used complete or truncated forms of LPS purified from different gram-negative bacteria and showed that the core oligosaccharides, but not lipid A, of the purified LPS are potent elicitors of PTI in pepper. Bedini and associates (2005) inferred that the coiled structures of the O-specific oligorhamnans can act as stimulators of PTI in A. thaliana, while Zeidler and colleagues (2004) showed that the lipid A moiety is as effective as intact LPS in inducing PTI in A. thaliana. The discrepancy in which LPS structures are important for inducing PTI might be due to the different plant species used in those studies, in which different plants may have developed their own LPS recognition systems to perceive LPS, or one plant simply has multiple receptors to recognize different parts of LPS. In this study, the Psy61 galU mutant with modified LPS and reduced
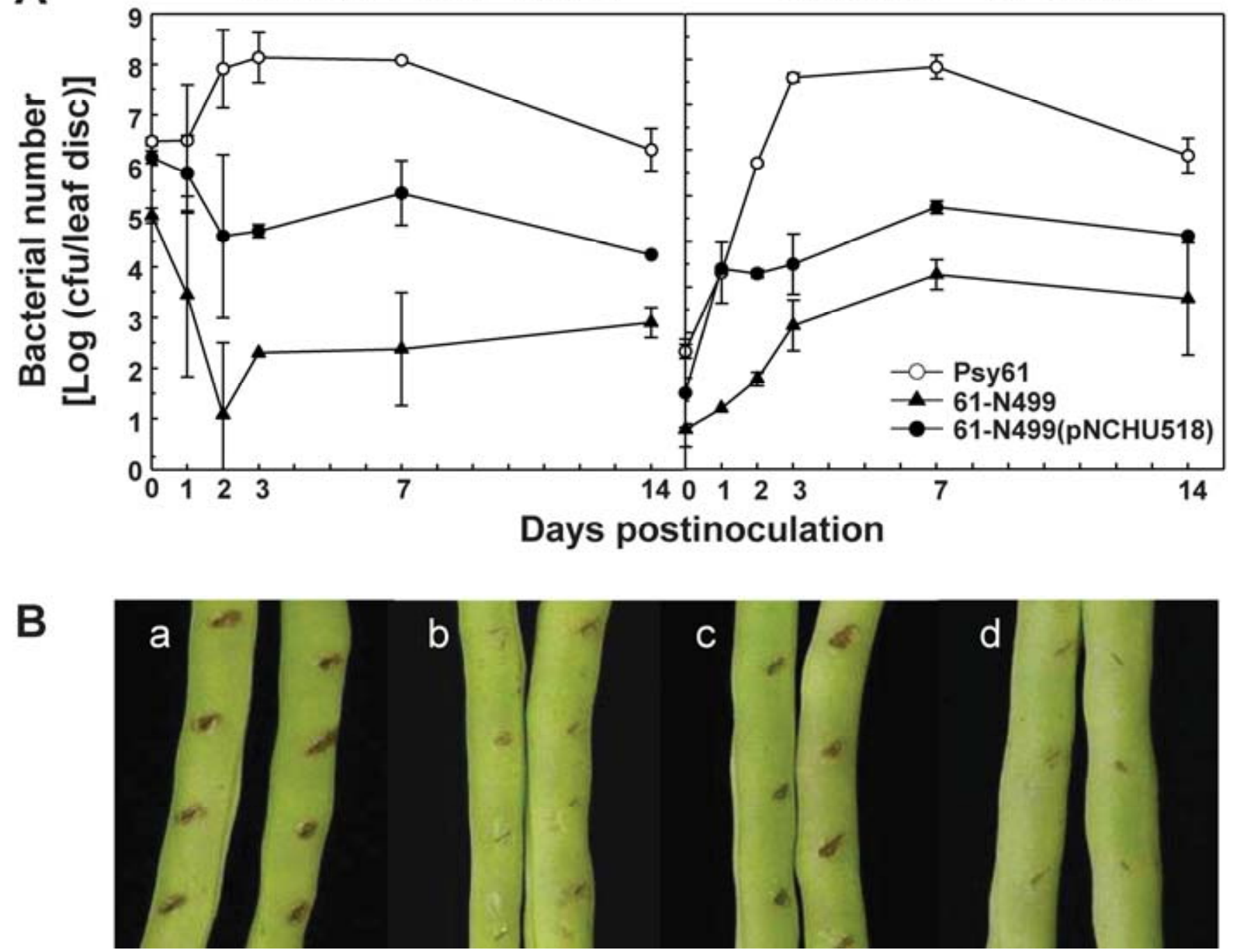

Fig. 6. Plant bioassays on bean $\mathbf{A}$, leaves and $\mathbf{B}$, pods. A, Leaves of 6-week-old bean plants were syringe infiltrated with Pseudomonas syringae pv. syringae 61 (Psy61), 61-N499 (galU mutant), and 61-N499 (pNCHU518) (complementing strain) at $10^{8}$ and $10^{5} \mathrm{CFU} / \mathrm{ml}$ (left and right panels, respectively). Leaf disks were harvested by a cork borer (diameter $=6 \mathrm{~mm}$ ), ground in $10 \mathrm{mM} \mathrm{MgCl}$ buffer, and spread onto King's B plates supplemented with appropriate antibiotics. Bacterial multiplication was enumerated at $0,1,2,3,7$, and 14 days postinoculation. Symbols represent the mean of three replications and vertical lines indicate standard deviations. B, Bean pods were inoculated by toothpick pricking method with a, Psy61 (wild type); b, 61-N499 (galU mutant); c, 61-N499 (pNCHU518) (complementing strain); and d, $\mathrm{H}_{2} \mathrm{O}$. Lesion formation was scored 7 days postinoculation. 
flagellation was capable of inducing PTI in tobacco and bean, suggesting that its surface-presenting PAMPs are effective triggers of PTI. The questions of whether the Psy61 galU mutation affects the number and structure of other PAMPs presenting on bacterial surfaces and whether its defective LPS could act as potent elicitor of PTI remain to be addressed. Once the issues are resolved, the galU mutant generated in this study may serve as a source of truncated LPS for a subsequent search of LPS receptors in plants.

LPS, the principal component of the outer membrane of gram-negative bacteria, is involved in maintaining the integrity of the outer membrane. LPS-deficient galU mutants showed aberrant localization of outer membrane proteins in enteric bacteria (Ames et al. 1974; Koplow and Goldfine 1974), leading to reduced secretion of flagellin and some virulence proteins (Komeda et al. 1977; Wandersman and Letoffe 1993; Sandlin et al. 1995). The expression and assembly of T3SS in the Psy61 galU mutant were assayed by monitoring the secretions of HrpZ1 and HopA1-Cya, two well-characterized T3S substrates (He et al. 1993; Wei et al. 2005), and the result in Figure 7 clearly showed that the galU mutant expressed and secreted HrpZ1 and HopA1-Cya at the level equivalent to the wild type, indicating that the structure of T3SS was not disrupted by the incomplete LPS structure under in vitro inducing conditions. In comparison, the electron micrographs of the $S$. flexneri wild type and its galU mutant show that they have similar numbers of T3SS needles emerging from the outer membrane, and the mutant secretes T3S effectors to bacterial milieu and has high invasive potential to cultured HeLa cells (West et al. 2005). In addition, the galU mutant of $P$. aeruginosa was not compromised in its ability to inject T3S effectors into cultured bronchial epithelial cells (Priebe et al. 2004). The results obtained from various galU mutants indicate that the defective LPS does not affect the assembly of T3SS in the outer membranes or its functions in secretion and translocation of T3S effectors under the in vitro assay conditions. However, in vivo analyses show that the mutations in galU exhibit characteristically different phenotypes between animal- and plantpathogenic bacteria. Upon infection of mice, the $P$. aeruginosa galU mutant showed attenuated virulence in corneal infection and minimal systemic spread in the lung but it can still elicit moderate to severe pneumonia that was confined to the lungs (Priebe et al. 2004). Viable counts of the P. aeruginosa galU mutant in mice lungs at $6 \mathrm{~h}$ post intranasal inoculation with an initial inoculum of $1 \times 10^{8} \mathrm{CFU}$ were approximately $1 \mathrm{log}$ lower than those of the wild-type strain. The galU mutation of Vibrio cholerae resulted in an approximate 50-fold reduction in colonization of the infant mouse small intestine (Nesper et

Table 2. Comparison of the hypersensitive response (HR)-inhibition level caused by the pretreatment of various agents

\begin{tabular}{|c|c|c|c|c|}
\hline \multirow[b]{2}{*}{ Agents used in pretreatment } & \multicolumn{4}{|c|}{$\begin{array}{l}\text { Average inhibition level of the } \\
\text { challenged HR per inoculum } \\
\text { concentration }(\mathrm{CFU} / \mathrm{ml})^{\mathrm{a}}\end{array}$} \\
\hline & $10^{8}$ & $10^{7}$ & $10^{6}$ & $\mathbf{0}$ \\
\hline Water & NA & NA & NA & 0 \\
\hline hrcC mutant $61-\mathrm{N} 393^{\mathrm{b}}$ & 4 & 3.5 & 0 & NA \\
\hline Heat-killed Psy61 & 3 & 2.5 & 0 & NA \\
\hline galU mutant 61-N499 & 2.5 & 1 & 0 & NA \\
\hline
\end{tabular}

${ }^{a}$ Leaf segments pretreated with bacteria or water were challenged $8 \mathrm{~h}$ later with HR-inducing Pseudomonas syringae pv. syringae 61 (Psy61) at 10 $\mathrm{CFU} / \mathrm{ml}$. The average level of HR inhibition was the mean of two inoculated leaves recorded from one representative experiment. Scale: 4 , complete inhibition of the HR; 3 , HR developed on approximately $25 \%$ of the co-injected area; 2, HR developed on approximately $50 \%$ of the co-injected area; 1, HR developed on approximately $75 \%$ of the coinjected area; 0, no inhibition of the HR; NA, nonapplicable. The experiment was repeated twice with similar results.

b 61-N393 harbored a nonpolar mutation in $h r c C$ coding for the outer membrane secretin protein of the type III secretion system.
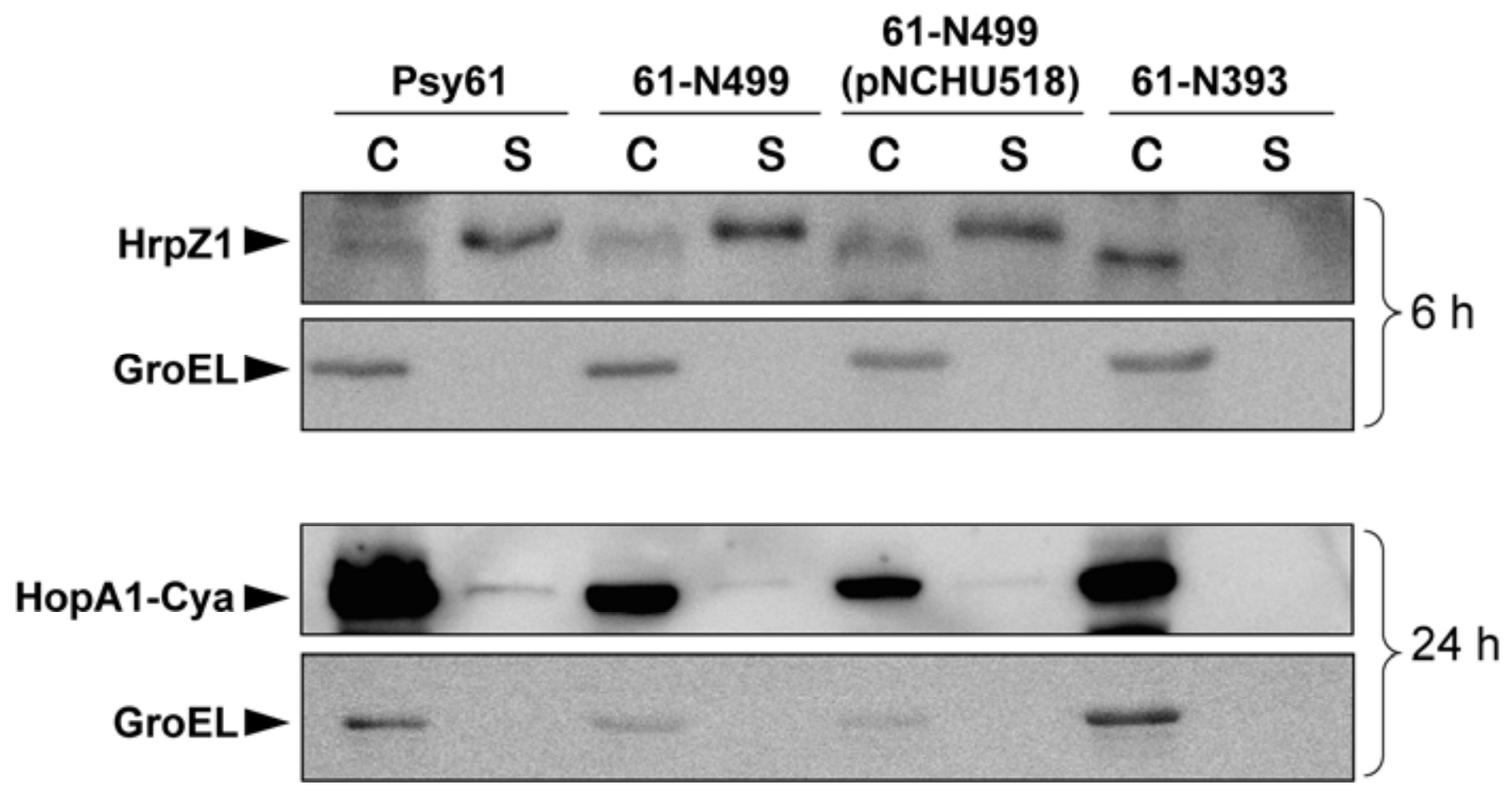

Fig. 7. Type III secretion system-dependent secretion of HrpZ1 and HopA1-Cya by Pseudomonas syringae pv. syringae 61 (Psy61), 61-N499 (galU mutant), and 61-N499 (pNCHU518) (complementing strain). Bacteria were grown in Hrp-derepressing medium (HrpMM) at $25^{\circ} \mathrm{C}$ for $6 \mathrm{~h}$ (for $\mathrm{HrpZ1}$ secretion) to 24 $\mathrm{h}$ (for HopA1-Cya secretion) and harvested by centrifugation at $15,000 \times \mathrm{g}$ for $30 \mathrm{~min}$ to obtain cell-bound (C) and supernatant (S) protein fractions. Proteins were resolved in $12 \%$ sodium dodecyl sulfate polyacrylamide gel electrophoresis and immunodetected by antibodies against HrpZ1, HopA1-Cya, and GroEL. The GroEL serves as a cytoplasmic marker in this experiment. 
al. 2001). In contrast, when the Psy61 galU mutant was tested in planta, it elicited null responses in both host and nonhost plants. The Psy61 galU mutant showed poor survival and no lesion formation during the 14-day incubation in bean leaves, and it lost the ability to trigger the HR in tobacco even though it has a complete set of T3SS and effector genes. The rapid reduction in the numbers of the viable cells of the Psy61 galU mutant immediately after infiltration let us hypothesize that, unlike the LPS-defective animal-pathogenic bacteria in their hosts, the metabolic activities of the Psy61 galU mutant cells are probably suppressed by host preformed defensive compounds or innate immune factors before they are able to express T3SS genes in planta. Previous researches on the hypersensitive reaction in plants revealed that the presence of living bacteria in the HR-induction period, varying from 0.5 to $4 \mathrm{~h}$ among different combinations of bacteria and plant species, is crucial for incompatible bacteria to launch the HR (Goodman and Novacky 1994; Klement et al. 1999), and inactivating bacterial metabolism with antibiotics (Goodman and Novacky 1994) or
PTI (also known as early induced resistance) (Klement et al. 1999) during the induction period prevents the development of $\mathrm{HR}$. The result of an in vitro $\mathrm{H}_{2} \mathrm{O}_{2}$ sensitivity assay (Table 1) shows that the galU mutant is more sensitive to hydrogen peroxide than the wild type, suggesting that the ROS-rich conditions induced by bacterial PAMPs in planta might abolish the cellular activities of the Psy61 galU mutant during the HRinduction period. Consequently, no HR or diseased responses were elicited in nonhost or host plants, respectively. The differences in host responses elicited by the galU mutants and their deleterious effects on bacterial survival suggest that the essence of innate immune mechanisms might be different between plants and animals, yet they are both effective to fight against bacterial infections.

The Psy61 galU mutant reproducibly induced a small number of dead cells in tobacco leaves (Fig. 4B), and it regained growth, although at the level of five orders of magnitude lower than that of the wild type, in bean leaves after 2 dpi (Fig. 6A), suggesting that the LPS-defective Psy61 galU mutant is not

\section{buffer}
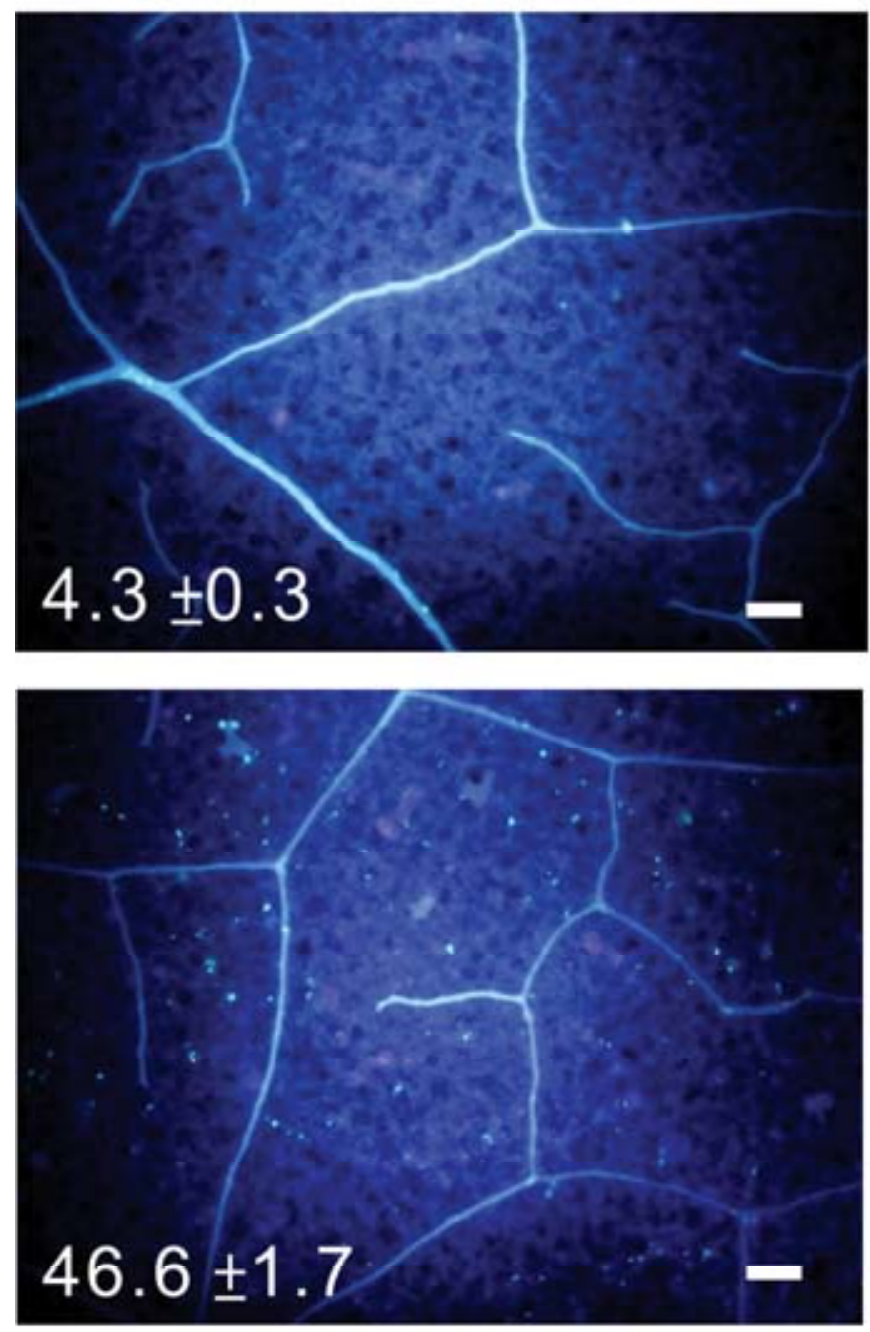

\section{$61-\mathrm{N} 499$}

\section{$61-\mathrm{N} 393$}
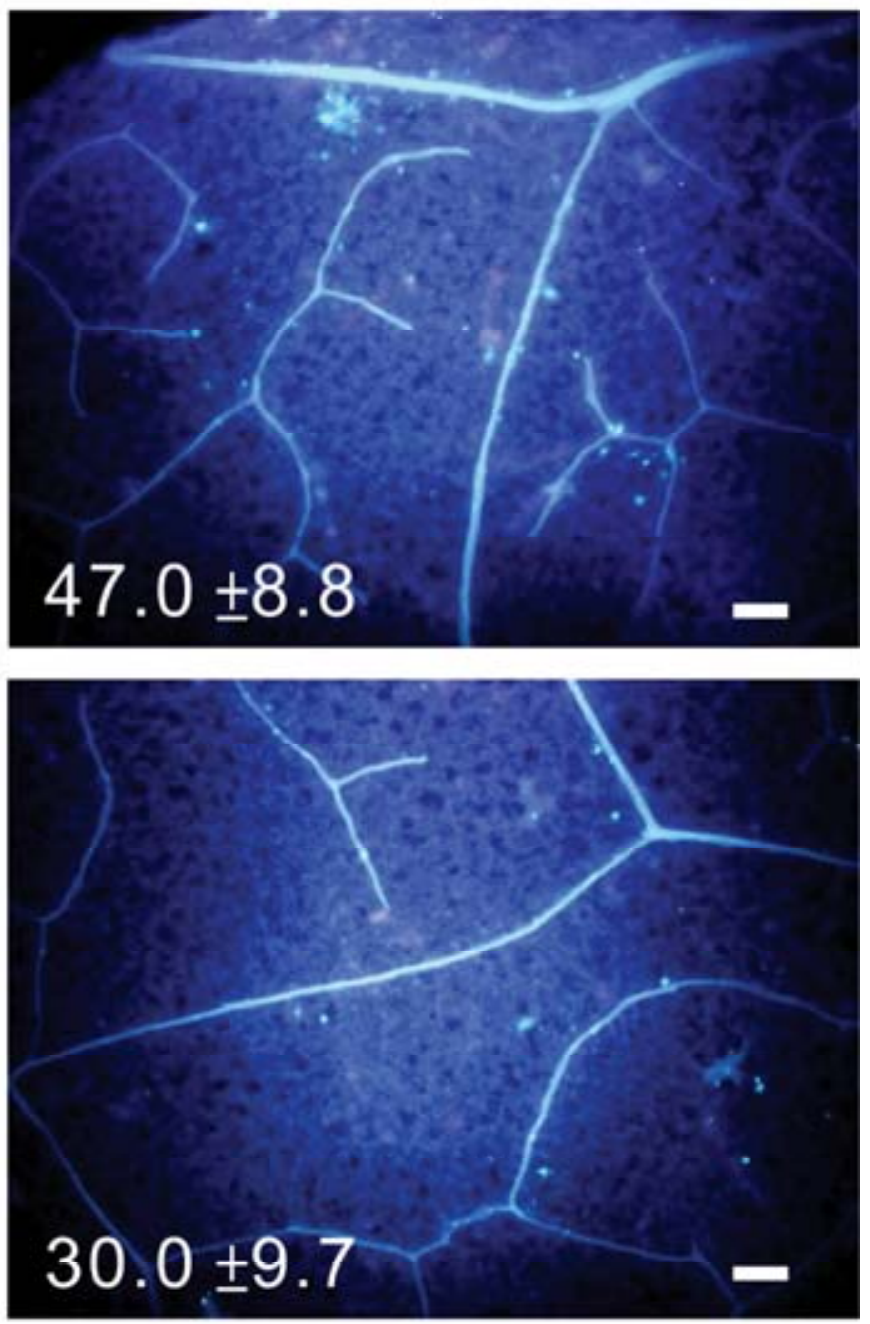

\section{Psy61}

Fig. 8. Elicitation of callose deposition in Nicotiana benthamiana by Pseudomonas syringae pv. syringae 61 (Psy61) and its derivatives. Tobacco leaves were infiltrated with (clockwise) buffer, 61-N393 ( $\mathrm{rcC}$ mutant), 61-N499 (galU mutant), and Psy61 (wild type) at $1 \times 10^{8} \mathrm{CFU} / \mathrm{ml}$. Leaf disks were collected at $12 \mathrm{~h}$ postinfiltration, stained with aniline blue, and visualized by an epifluorescence microscope. For each treatment, the average number of callose depositions per field of view \pm standard deviation $(n=10)$ is shown at the lower left corner of the micrograph. Bar $=100 \mu \mathrm{m}$. 
impaired in its ability to translocate $\mathrm{T} 3 \mathrm{~S}$ effectors into plant cells once they can survive the killing effect of PTI. Attempts to use HopA1-Cya fusion protein as a reporter (Schechter et al. 2004; Wei et al. 2005) for a translocation assay in the Psy61 galU mutant produced values below detection limits, which is most likely due to the fact that only a few bacterial cells can survive PTI to translocate the HopA1-Cya fusion protein (H.C. Huang, unpublished data). Taken together, our results reveal that the LPS of plant-pathogenic bacteria, similar to its counterparts in animal-pathogenic bacteria, play important roles in the early stage of pathogen-plant interactions leading to successful recognition and infection.

\section{MATERIALS AND METHODS}

\section{Bacterial strains, culture conditions, plasmids, and DNA manipulation techniques.}

Bacterial strains and plasmids used in this study are described in the text. Conditions for culturing Escherichia coli and P. syringae strains have been described (Deng et al. 1998). Cloning and DNA manipulations were done in E. coli DH10B using standard procedures (Sambrook et al. 1989). A pUC18-based genomic library was constructed by partially digesting the genomic DNA of Psy61 with Sau3A, followed by cloning 4- to 5 -kb fragments into pUC18. Constructed plasmids were transformed into $E$. coli FF4001 that has a mutation in galU (Brede et al. 1991). For the galactose sensitivity test, MacConkeygalactose agar was prepared with Difco MacConkey agar base (BD Diagnostic Systems, Franklin Lakes, NJ, U.S.A.) supplemented with $0.2 \%$ galactose. A motility assay was carried out on a $0.3 \%$ Hrp derepressing agar medium (HrpMM) (Huynh et al. 1989) at $28^{\circ} \mathrm{C}$ for 2 days. In vitro activity of the T3SS was assayed by the secretion of HrpZ1 and HopA1-Cya into culture medium. Bacteria expressing HopA1-Cya chimeric protein was obtained by electroporating pNCHU1623, a pBBR1MCS5 (Kovach et al. 1995) derivative harboring a 3-kb BamHISacI fragment of hopAl-cya fusion gene from pNCHU1180 (Wei et al. 2005), into the wild-type Psy61, galU mutant 61N499, complementing strain 61-N499 (pNCHU518), and hrcC mutant 61-N393 (Deng et al. 1998). Bacteria were first grown in $\mathrm{KB}$ broth to an optical density at $600 \mathrm{~nm}\left(\mathrm{OD}_{600}\right)$ of 0.8 and transferred to HrpMM for inducing the expression of hrp genes at $25^{\circ} \mathrm{C}$ for 6 and $24 \mathrm{~h}$ for HrpZ1 and HopA1-Cya secretion assays, respectively (Deng et al. 1998). GroEL was used as a cellular marker to monitor cellular integrity during the secretion assays. Immunodetections of HrpZ1, HopA1Cya, and GroEL proteins were performed as described (Wei et al. 2005) using HrpZ1 antiserum, mouse monoclonal Cya A (3D1) antibody (Santa Cruz Biotechnology, Santa Cruz, CA, U.S.A.), and rabbit polyclonal GroEL (from E. coli) antibody (Assay Designs, Ann Arbor, MI, U.S.A.) at the ratios of 1/500, $1 / 5,000$, and 1/2,000, respectively. Antibiotics were added to the culture medium at the following concentrations: ampicillin at $100 \mu \mathrm{g} / \mathrm{ml}$, kanamycin at $50 \mu \mathrm{g} / \mathrm{ml}$, tetracycline at $20 \mu \mathrm{g} / \mathrm{ml}$, and nalidixic acid at $20 \mu \mathrm{g} / \mathrm{ml}$. DNA sequences were analyzed with DNAStar software (DNAStar Inc., Madison, WI, U.S.A.). Database searches for homology, computer-aided amino acid sequence prediction, and percent similarity calculation were performed using the BLAST programs (Altschul et al. 1997) at the National Center for Biotechnology Information.

\section{Construction of galU mutation in Psy61 by marker-exchange strategy.}

A 494-bp deletion at the $3^{\prime}$ end of the 840-bp galU gene of Psy61 was constructed by subcloning border fragments into restriction sites on either side of a kanamycin-resistant cassette lacking a transcription terminator in pRK415 to produce
pNCHU499 that was conjugated into Psy61 by triparental mating, followed by screening and selecting for marker-exchanged mutant 61-N499, as described (Deng et al. 1998). Mutant construction was confirmed by Southern hybridization using standard procedures (Sambrook et al. 1989). The complementing plasmid, pNCHU518, was generated by cloning a $2.7-\mathrm{kb}$ fragment containing the entire galU gene and its flanking regions into pRK415, which was conjugated into the galU mutant 61N499 by triparental mating.

\section{UDP-GIc pyrophosphorylase assay.}

The enzymatic activity of UDP-Glc pyrophosphorylase was assayed by quantitative measurement of glucose-1-phosphate (Glc1P) production according to Duggleby and associates (1996). The protein concentration of sonicated cell extracts was determined by Bradford assay according to the manufacturer's instruction (Bio-Rad, Hercules, CA, U.S.A.). Each reaction mixture contained $100 \mathrm{mM}$ Tris- $\mathrm{HCl}(\mathrm{pH} 8.0), 2 \mathrm{mM}$ $\mathrm{MgCl}_{2}, 1 \mathrm{mM}$ 2-mercaptoethanol, $1 \mathrm{mM}$ UDP-Glc, $8 \mu \mathrm{M}$ glucose 1,6-diphosphate, $1 \mathrm{mM}$ NADP, $1 \mathrm{mM} \mathrm{NaPPi}, 5$ units each of phosphoglucomutase (PGM) and glucose 6-phosphate dehydrogenase (G6PD), and cell extracts at a final volume of 1 $\mathrm{ml}$. Reactions were performed at $37^{\circ} \mathrm{C}$ for $15 \mathrm{~min}$, and the reduction of $\mathrm{NADP}^{+}$was measured at $\mathrm{OD}_{340}$. The synthesis of NADPH was accompanied by the oxidation of Glc1P at the molar ratio of $1: 1$, following the biochemical reactions of Glc1P (PGM) $\rightarrow$ Glc6P, Glc6P + NADP ${ }^{+}$(G6PD) $\rightarrow$ 6-phosphogluconate + NADPH (the enzyme for catalyzing the reaction is shown in parentheses). Therefore, the UDP-Glc PPase activity was defined as the amount (in nmole) of NADPH synthesized per minute per milligram of total protein.

\section{Electron microscopy observation.}

$P$. syringae strains grown on $\mathrm{KB}$ agar plates were suspended in sterile distilled water. The cell suspension was placed onto a carbon-coated copper grid, stained with $2 \%$ uranyl acetate (Sigma-Aldrich, St. Louis), and examined by TEM (JEM1200CX II; JEOL, Tokyo) at $80 \mathrm{kV}$.

\section{Biofilm formation.}

The biofilm production assay was performed as described by Djordjevic and associates (2002) with a slight modification. Overnight-grown $P$. syringae strains in $\mathrm{KB}$ broth at $28^{\circ} \mathrm{C}$ were harvested by centrifugation, adjusted to an $\mathrm{OD}_{600}$ of 0.5 with $\mathrm{KB}$ broth, diluted 10-fold with the same medium, and $200 \mu \mathrm{l}$ of the diluted bacteria was transferred with eight replicates per strain into the wells of polystyrene microtitration plates (Greiner Bio-one GmbH, Solingen, Germany) that were previously rinsed with $70 \%$ ethanol for surface sterilization and air dried. Wells containing the assay medium without bacteria were used as negative controls. Plates were sealed with plastic wrap and incubated at $28^{\circ} \mathrm{C}$ for $70 \mathrm{~h}$ without shaking. After incubation, the plate wells were washed five times with sterile distilled water, air dried for $45 \mathrm{~min}$, and stained with $200 \mu \mathrm{l}$ of $0.5 \%$ (wt/vol) crystal violet solution for $45 \mathrm{~min}$. After staining, plates were washed five times with sterile distilled water, air dried, and destained with $95 \%$ ethanol (200 $\mu$ per well) followed by transferring $150 \mu \mathrm{l}$ of the destained solution to a new microtitration plate for a spectrophotometric measurement at $\mathrm{OD}_{595}$.

\section{$\mathrm{H}_{2} \mathrm{O}_{2}$ sensitivity assay.}

Sensitivity of Psy61 and the galU mutant 61-N499 to hydrogen peroxide was assayed at $28^{\circ} \mathrm{C}$ by a paper-disk diffusion test. Paper disks (6 $\mathrm{mm}$ in diameter) soaked in $0.1 \%$ (vol/vol) hydrogen peroxide were placed in the center of $\mathrm{KB}$ agar plates that had been spread with $100 \mu \mathrm{l}$ of $10^{7} \mathrm{CFU} / \mathrm{ml}$ bacterial sus- 
pensions. The diameter (in millimeters) of growth inhibition zone was recorded at $2 \mathrm{dpi}$.

\section{LPS preparation and silver staining.}

LPS was prepared by a modified phenol-water method (Goldman and Leive 1987). All steps were carried out at $4{ }^{\circ} \mathrm{C}$ unless specified. In brief, 2-ml bacterial cells $\left(\mathrm{OD}_{600}=0.3\right)$ in phosphate-buffered saline (PBS, $\mathrm{pH}$ 7.2) were centrifuged and washed once in PBS containing $0.15 \mathrm{mM} \mathrm{CaCl}_{2}$ and $0.5 \mathrm{mM}$ $\mathrm{MgCl}_{2}$. The bacterial pellets were resuspended in $300 \mu \mathrm{l}$ of $\mathrm{H}_{2} \mathrm{O}$ and extracted with an equal volume of hot phenol (60 to $70^{\circ} \mathrm{C}$ ) by vigorous stirring at 65 to $70^{\circ} \mathrm{C}$ for $15 \mathrm{~min}$. Next, the suspension was chilled on ice and centrifuged at $8,500 \times g$ for $15 \mathrm{~min}$, and the phenol phase was re-extracted with $300 \mu \mathrm{l}$ of $\mathrm{H}_{2} \mathrm{O}$. The aqueous phase of two extractions was collected and precipitated with $0.5 \mathrm{M}$ sodium acetate (final concentration) and 10 volumes of $95 \%$ ethanol at $-20^{\circ} \mathrm{C}$ overnight. The LPS pellet was obtained by centrifugation at $2,000 \times g$ for $10 \mathrm{~min}$, resuspended in $100 \mu \mathrm{l}$ of $\mathrm{H}_{2} \mathrm{O}$, and precipitated with the ethanol again. The precipitated LPS was dried, resuspended in 50 $\mu \mathrm{l}$ of $\mathrm{H}_{2} \mathrm{O}$, resolved by $12 \%$ SDS-PAGE gel, and detected by silver staining as described by Dubray and Bezard (1982). In brief, the SDS-PAGE gel was fixed in acid-alcohol solution (25\% isopropyl alcohol and $10 \%$ acetic acid) at room temperature overnight, followed by a wash with $7.5 \%$ acetic acid for $30 \mathrm{~min}$. The fixed gel was treated with $0.2 \%$ periodic acid at $4^{\circ} \mathrm{C}$ for $1 \mathrm{~h}$, washed three times with distilled water, and silver stained for $30 \mathrm{~min}$ at room temperature with a freshlymade staining solution prepared in the following order: i) add $1.4 \mathrm{ml}$ of $25 \%$ ammonia solution to $21 \mathrm{ml}$ of $0.36 \% \mathrm{NaOH}$, ii) add $4 \mathrm{ml}$ of $20 \%$ silver nitrate slowly while agitating vigorously, and iii) add $83.6 \mathrm{ml}$ of $\mathrm{H}_{2} \mathrm{O}$. The stained gel was transferred to a freshly prepared developer solution containing $0.05 \%$ citric acid, $0.019 \%$ formaldehyde solution, and $10 \%$ methanol, and the staining process was terminated when the LPS bandings appeared dark brown by washing the gel with $1 \%$ acetic acid for a few minutes, followed by several washes with distilled water.

\section{Flagellin purification and glycosylation detection.}

For flagellin purification, all steps were performed according to Taguchi and associates $(2003)$ at $4^{\circ} \mathrm{C}$ unless specified. $P$. syringae strains were grown in $5 \mathrm{ml}$ of Luria-Bertani medium supplemented with $10 \mathrm{mM} \mathrm{MgCl}$ for $24 \mathrm{~h}$ at $25^{\circ} \mathrm{C}$ and transferred to $60 \mathrm{ml}$ of $\mathrm{HrpMM}$ for $24 \mathrm{~h}$ of incubation at $23^{\circ} \mathrm{C}$ (Huynh et al. 1989). A 200- $\mu$ l aliquot of bacterial suspension containing bacterial cells and culture medium was saved for subsequent immunodetection of total flagellins (TF) with FilC antiserum. The rest of the bacterial cells were harvested by centrifugation at $7,000 \times g$ for $10 \mathrm{~min}$ and resuspended in a phosphate buffer ( $50 \mathrm{mM}$ sodium phosphate, $\mathrm{pH} 7.0$ ) by vigorous vortex to shear off flagella. Sheared flagella in the supernatant were collected by repeated centrifugation at $10,000 \times g$ for $30 \mathrm{~min}$ to remove the remaining intact cells and, finally, by ultrahigh-speed centrifugation at $100,000 \times g$ for $30 \mathrm{~min}$ to obtain sedimented flagella (SF). The SF was suspended in 300 $\mu \mathrm{l}$ of $\mathrm{H}_{2} \mathrm{O}$ and stored at $-20^{\circ} \mathrm{C}$. For immunodetection of flagellins, the fractions of TF and SF were denatured in $2 \times$ sample buffer, separated by a $12 \%$ SDS-PAGE gel, electrotransferred to Immobilon-P membrane, and probed with FliC antibody (kindly provided by Y. Ichinose, Okayama University, Japan) at a ratio of $1 / 5,000$, followed by alkaline phosphatase-conjugated anti-mouse immunoglobulin $\mathrm{G}$ antibody (Boehringer Mannheim GmbH, Mannheim, Germany) for chemiluminescent detection using CDP-Star (Applied Biosystems, Bedford, MA, U.S.A.) as a substrate. The detection of glycoprotein was carried out using a Pierce GelCode glycoprotein staining kit
(Thermo Fisher Scientific Inc. Rockford, IL, U.S.A.) according to the manufacturer's instruction.

\section{Plant bioassays.}

Tobacco (N. tabacum L. cv. Van-Hicks and N. benthamiana) and snap bean (Phaseolus vulgaris L. cv. Eagle) plants were grown under greenhouse conditions at 23 to $25^{\circ} \mathrm{C}$ with a photoperiod of 16 to $24 \mathrm{~h}$ until the six-leaf stage, and transferred to the laboratory for bioassays. For HR elicitation assays, bacteria were grown overnight on KB agar supplemented with appropriate antibiotics, suspended in distilled water at a density of $10^{8} \mathrm{CFU} / \mathrm{ml}$, and then infiltrated with a needless syringe into the interveinals of tobacco leaves (Huang et al. 1988). HR development was observed within $24 \mathrm{~h}$ at room temperature. The HR inhibition test was performed to test the LPS-induced basal resistance using wild-type Psy61 as the challenging strain (infiltrated at $10^{7} \mathrm{CFU} / \mathrm{ml}$ ) that was inoculated at $8 \mathrm{hpi}$ with serially diluted bacteria (heat-killed wild-type Psy61, hrc C mutant 61-N393, and galU mutant 61-N499) at $10^{8}, 10^{7}$, and $10^{6} \mathrm{CFU} / \mathrm{ml}$. For bacterial multiplication assays in susceptible bean leaves, the bacteria were suspended in distilled water at $10^{5}$ and $10^{8} \mathrm{CFU} / \mathrm{ml}$ for syringe infiltration as described above. Bean plants were incubated in a humid growth chamber (relative humidity $=90 \%$ ) with a light intensity of $150 \mu \mathrm{E} / \mathrm{cm}^{2}$ and a photoperiod of $12 \mathrm{~h}$ at 25 to $28^{\circ} \mathrm{C}$, and leaf disks were sampled 0 to $14 \mathrm{dpi}$ for bacterial enumeration, as previously described (Deng et al. 1998).

\section{Callose deposition assay.}

Six-week-old $N$. benthamiana leaves were infiltrated with Psy61 and its derivatives at a concentration of $1 \times 10^{8} \mathrm{CFU} / \mathrm{ml}$ by a blunt syringe. Leaf disks were harvested at $12 \mathrm{hpi}$; cleared with alcoholic lactophenol (1:1:1:1:8 phenol/glycerol/lactic $\mathrm{acid} /$ water/ethanol); rinsed sequentially in ethanol, then water; and stained with aniline blue solution $(0.01 \%$ aniline blue [Sigma-Aldrich] in $150 \mathrm{mM} \mathrm{K} \mathrm{HPO}_{4}, \mathrm{pH} 9.5$ ) for $60 \mathrm{~min}$ as previously described (Underwood et al. 2007). Stained leaf disks were examined by an epifluorescent microscope (Olympus IX71) equipped with a 365-nm excitation filter and a 450$\mathrm{nm}$ emission filter. The number of callose depositions was determined with Image J software (National Institute of Health, Bethesda, MD, U.S.A.). More than 10 microscopic fields (2.28 $\mathrm{mm}^{2}$ per field of view) taken from three independent leaves were analyzed and calculated to get the means and standard deviations of callose deposits that are shown in Figure 8. The callose deposition assays reported here have been performed three times with similar results.

\section{Nucleotide sequence accession number.}

The nucleotide sequence of a 2,742-bp DNA fragment containing galU and gor genes has been deposited in GenBank database under accession number EU833989.

\section{ACKNOWLEDGMENTS}

We thank Y. Ichinose (Okayama University, Japan) for providing FliC antiserum and C.-C. Hu and W.-H. Ko for critical review of the manuscript. This work was supported by NSC grants NSC93-2317-B-005009 and NSC94-2317-B-005-012.

\section{LITERATURE CITED}

Abramovitch, R. B., Kim, Y. J., Chen, S., Dickman, M. B., and Martin, G. B. 2003. Pseudomonas type III effector AvrPtoB induces plant disease susceptibility by inhibition of host programmed cell death. EMBO (Eur. Mol. Biol. Organ.) J. 22:60-69.

Altschul, S. F., Madden, T. L., Schaffer, A. A., Zhang, J., Zhang, Z., Miller, W., and Lipman, D. J. 1997. Gapped BLAST and PSI-BLAST: 
A new generation of protein database search programs. Nucleic Acids Res. 25:3389-3402.

Ames, G. F., Spudich, E. N., and Nikaido, H. 1974. Protein composition of outer membrane of Salmonella typhimurium: Effect of lipopolysaccharide mutations. J. Bacteriol. 117:406-416.

Beattie, G. A., and Lindow, S. E. 1994. Epiphytic fitness of phytopathogenic bacteria: Physiological adaptations for growth and survival. Pages 1-27 in: Bacterial Pathogenesis of Plants and Animals-Molecular and Cellular Mechanisms. Vol. 192. J. L. Dangl, ed. Springer-Verlag, Berlin.

Bedini, E., De Castro, C., Erbs, G., Mangoni, L., Dow, J. M., Newman, M. A., Parrilli, M., and Unverzagt, C. 2005. Structure-dependent modulation of a pathogen response in plants by synthetic O-antigen polysaccharides. J. Am. Chem. Soc. 127:2414-2416.

Brede, G., Fjaervik, E., and Valla, S. 1991. Nucleotide sequence and expression analysis of the Acetobacter xylinum uridine diphosphoglucose pyrophosphorylase gene. J. Bacteriol. 173:7042-7045.

Brown, I., Mansfield, J., and Bonas, U. 1995. hrp Genes in Xanthomonas campestris pv. vesticatoria determine ability to suppress papilla deposition in pepper mesophyll cells. Mol. Plant-Microbe Interact. 8:825-836.

Chang, H. Y., Lee, J. H., Deng, W. L., Fu, T. F., and Peng, H. L. 1996 Virulence and outer membrane properties of a galU mutant of Klebsiella pneumoniae CG43. Microb. Pathog. 20:255-261.

Chang, H.-Y., Huang, H.-C., Lee, J.-H., and Peng, H.-L. 1999. Characterization of a putative Pseudomonas UDP-glucose pyrophosphorylase. Proc. Natl. Sci. Counc. R.O.C. (B) 23:74-84.

Collmer, A., Badel, J. L., Charkowski, A. O., Deng, W.-L., Fouts, D. E., Ramos, A. R., Rehm, A. H., Anderson, D. M., Schneewind, O., van Dijk, K., and Alfano, J. R. 2000. Pseudomonas syringae Hrp type III secretion system and effector proteins. Proc. Natl. Acad. Sci. U.S.A. 97:8770-8777.

DebRoy, S., Thilmony, R., Kwack, Y. B., Nomura, K., and He, S. Y. 2004 A family of conserved bacterial effectors inhibits salicylic acid-mediated basal immunity and promotes disease necrosis in plants. Proc. Natl. Acad. Sci. U.S.A. 101:9927-9932

Deng, W. L., Preston, G., Collmer, A., Chang, C. J., and Huang, H. C. 1998. Characterization of the $h r p C$ and $h r p R S$ operons of Pseudomonas syringae pathovars syringae, tomato, and glycinea and analysis of the ability of $h r p F, h r p G, h r c C, h r p T$, and $h r p V$ mutants to elicit the hypersensitive response and disease in plants. J. Bacteriol. 180:4523-4531.

Desaki, Y., Miya, A., Venkatesh, B., Tsuyumu, S., Yamane, H., Kaku, H., Minami, E., and Shibuya, N. 2006. Bacterial lipopolysaccharides induce defense responses associated with programmed cell death in rice cells. Plant Cell Physiol. 47:1530-1540.

Djordjevic, D., Wiedmann, M., and McLandsborough, L. A. 2002. Microtiter plate assay for assessment of Listeria monocytogenes biofilm formation. Appl. Environ. Microbiol. 68:2950-2958.

Dow, J. M., Newman, M. A., and von Roepenack, E. 2000. The induction and modulation of plant defense responses by bacterial liposaccharides. Annu. Rev. Phytopathol. 38:241-261.

Dubray, G., and Bezard, G. 1982. A highly sensitive periodic acid-silver stain for 1,2-diol groups of glycoproteins and polysaccharides in polyacrylamide gels. Anal. Biochem. 119:325-329.

Duggleby, R. G., Peng, H. L., and Chang, H. Y. 1996. An improved assay for UDP glucose pyrophosphorylase and other enzymes that have nucleotide products. Experientia 52:568-572.

Finlay, B. B., and McFadden, G. 2006. Anti-immunology: Evasion of the host immune system by bacterial and viral pathogens. Cell 124:767782 .

Goldman, R. C., and Leive, L. 1987. Electrophoretic separation of liposaccharide monomers differing in polysaccharide length. Methods Enzymol. 138:267-275.

Goodman, R. M., and Novacky, A. J. 1994. The hypersensitive reaction in plants to pathogens. The American Phytopathological Society, St. Paul, MN, U.S.A

Hauck, P., Thilmony, R., and He, S. Y. 2003. A Pseudomonas syringae type III effector suppresses cell wall-based extracellular defense in susceptible Arabidopsis plants. Proc. Natl. Acad. Sci. U.S.A. 100:85778582.

He, P., Shan, L., and Sheen, J. 2007. Elicitation and suppression of microbeassociated molecular pattern-triggered immunity in plant-microbe interactions. Cell. Microbiol. 9:1385-1396.

He, S. Y., Huang, H. C., and Collmer, A. 1993. Pseudomonas syringae pv. syringae harpin ${ }_{\mathrm{Pss}}$ : A protein that is secreted via the Hrp pathway and elicits the hypersensitive response in plants. Cell 73:1255-1266.

Huang, H. C., Schuurink, R., Denny, T. P., Atkinson, M. M., Baker, C. J., Yucel, I., Hutcheson, S. W., and Collmer, A. 1988. Molecular cloning of a Pseudomonas syringae pv. syringae gene cluster that enables Pseudomonas fluorescens to elicit the hypersensitive response in tobacco plants. J. Bacteriol. 170:4748-4756.

Huang, H. C., Lin, R. H., Chang, C. J., Collmer, A., and Deng, W. L. 1995.
The complete hrp gene cluster of Pseudomonas syringae pv. syringae 61 includes two blocks of genes required for harpin ${ }_{\text {Pss }}$ secretion that are arranged colinearly with Yersinia ysc homologs. Mol. Plant-Microbe Interact. 8:733-746.

Huynh, T. V., Dahlbeck, D., and Staskawicz, B. J. 1989. Bacterial blight of soybean: Regulation of a pathogen gene determining host cultivar specificity. Science 245:1374-1377.

Jayaswal, R. K., Bressan, R. A., and Handa, A. K. 1985. Effects of a mutation that eliminates UDP glucose-pyrophosphorylase on the pathogenicity of Erwinia carotovora subsp. carotovora. J. Bacteriol. 164:473-476.

Jones, J. D., and Dangl, J. L. 2006. The plant immune system. Nature 444:323-329

Keen, N. T., Tamaki, S., Kobayashi, D., and Trollinger, D. 1988. Improved broad-host-range plasmids for DNA cloning in gram-negative bacteria. Gene 70:191-197.

Klement, Z., Bozso, Z., Ott, P. G., Kecskes, M. L., and Rudolph, K. 1999. Symptomless resistant response instead of the hypersensitive reaction in tobacco leaves after infiltration of heterologous pathovars of Pseudomonas syringae. J. Phytopathol. 147:467-475.

Klement, Z., Bozso, Z., Kecskes, M. L., Besenyei, E., Arnold, C., and Ott, P. G. 2003. Local early induced resistance of plants as the first line of defence against bacteria. Pest Manage. Sci. 59:465-474.

Komeda, Y., Icho, T., and Iino, T. 1977. Effects of galU mutation on flagellar formation in Escherichia coli. J. Bacteriol. 129:908-915.

Koplow, J., and Goldfine, H. 1974. Alteration in the outer membrane of the cell envelope of heptose-deficient mutants of Escherichia coli. J. Bacteriol. 117:527-543.

Kovach, M. E., Elzer, P. H., Hill, D. S., Robertson, G. T., Farris, M. A., Roop II, R. M., and Peterson, K. M. 1995. Four new derivatives of the broad-host-range cloning vector pBBR1MCS, carrying different antibiotic-resistance cassettes. Gene 166:175-176.

Leeman, M., van Pelt, J. A., den Ouden, F. M., Heinsbroek, M., Bakker, P. A. H. M., and Schippers, B. 1995. Induction of systemic resistance against Fusarium wilt of radish by lipopolysaccharides of Pseudomonas fluorescens. Phytopathology 85:1021-1027.

Miller, S. I., Ernst, R. K., and Bader, M. W. 2005. LPS, TLR4 and infectious disease diversity. Nat. Rev. Microbiol. 3:36-46.

Mishina, T. E., and Zeier, J. 2007. Pathogen-associated molecular pattern recognition rather than development of tissue necrosis contributes to bacterial induction of systemic acquired resistance in Arabidopsis. Plant J. 50:500-513.

Mudgett, M. B. 2005. New insights to the function of phytopathogenic bacterial Type III effectors in plants. Annu. Rev. Plant Biol. 56:509-531.

Nesper, J., Lauriano, C. M., Klose, K. E., Kapfhammer, D., Kraiss, A., and Reidl, J. 2001. Characterization of Vibrio cholerae O1 El for galU and galE mutants: Influence on lipopolysaccharide structure, colonization, and biofilm formation. Infect. Immun. 69:435-445.

Newman, M. A., Daniels, M. J., and Dow, J. M. 1997. The activity of lipid A and core components of bacterial lipopolysaccharides in the prevention of the hypersensitive response in pepper. Mol. Plant-Microbe Interact. 10:926-928.

Newman, M. A., Dow, J. M., and Daniels, M. J. 2001. Bacterial liposaccharides and plant-pathogen interactions. Eur. J. Plant Pathol. 107:95102.

Newman, M. A., von Roepenack-Lahaye, E., Parr, A., Daniels, M. J., and Dow, J. M. 2002. Prior exposure to lipopolysaccharide potentiates expression of plant defenses in response to bacteria. Plant J. 29:487-495.

Ott, P. G., Varga, G. J., Szatmari, A., Bozso, Z., Klement, E., Medzihradszky, K. F., Besenyei, E., Czelleng, A., and Klement, Z. 2006. Novel extracellular chitinases rapidly and specifically induced by general bacterial elicitors and suppressed by virulent bacteria as a marker of early basal resistance in tobacco. Mol. Plant-Microbe Interact. 19:161-172.

Priebe, G. P., Dean, C. R., Zaidi, T., Meluleni, G. J., Coleman, F. T., Coutinho, Y. S., Noto, M. J., Urban, T. A., Pier, G. B., and Goldberg, J. B. 2004. The galU gene of Pseudomonas aeruginosa is required for corneal infection and efficient systemic spread following pneumonia but not for infection confined to the lung. Infect. Immun. 72:4224-4232

Reitz, M., Rudolph, K., Schroder, I., Hoffmann-Hergarten, S., Hallmann, J., and Sikora, R. A. 2000. Lipopolysaccharides of Rhizobium etli strain $\mathrm{G} 12$ act in potato roots as an inducing agent of systemic resistance to infection by the cyst nematode Globodera pallida. Appl. Environ. Microbiol. 66:3515-3518.

Sambrook, J., Fritsch, E. F., and Maniatis, T. 1989. Molecular Cloning: A Laboratory Manual. Cold Spring Harbor Laboratory Press, Cold Spring Harbor, NY, U.S.A

Sandlin, R. C., Lampel, K. A., Keasler, S. P., Goldberg, M. B., Stolzer, A. L., and Maurelli, A. T. 1995. Avirulence of rough mutants of Shigella flexneri: Requirement of $\mathrm{O}$ antigen for correct unipolar localization of Ics A in the bacterial outer membrane. Infect. Immun. 63.229-237. 
Schechter, L. M., Roberts, K. A., Jamir, Y., Alfano, J. R., and Collmer, A. 2004. Pseudomonas syringae type III secretion system targeting signals and novel effectors studied with a Cya translocation reporter. J. Bacteriol. 186:543-555.

Schulman, H., and Kennedy, E. P. 1977. Identification of UDP-glucose as intermediate in the biosynthesis of the membrane-derived oligosaccharides of Escherichia coli. J. Biol. Chem. 252:6299-6303.

Schwessinger, B., and Zipfel, C. 2008. News from the frontline: Recent insights into PAMP-triggered immunity in plants. Curr. Opin. Plant Biol. 11:389-395.

Silipo, A., Molinaro, A., Sturiale, L., Dow, J. M., Erbs, G., Lanzetta, R. Newman, M. A., and Parrilli, M. 2005. The elicitation of plant innate immunity by lipooligosaccharide of Xanthomonas campestris. J. Biol. Chem. 280:33660-33668.

Taguchi, F., Shimizu, R., Inagaki, Y., Toyoda, K., Shiraishi, T., and Ichinose, Y. 2003. Post-translational modification of flagellin determines the specificity of HR induction. Plant Cell Physiol. 44:342-349.

Taguchi, F., Shibata, S., Suzuki, T., Ogawa, Y., Aizawa, S., Takeuchi, K., and Ichinose, Y. 2008. Effects of glycosylation on swimming ability and flagellar polymorphic transformation in Pseudomonas syringae pv. tabaci 6605. J. Bacteriol. 190:764-768.

Underwood, W., Zhang, S., and He, S. Y. 2007. The Pseudomonas syringae type III effector tyrosine phosphatase HopAO1 suppresses innate immunity in Arabidopsis thaliana. Plant J. 52:658-672.

Van Wees, S. C., Pieterse, C. M., Trijssenaar, A., Van't Westende, Y. A.,
Hartog, F., and Van Loon, L. C. 1997. Differential induction of systemic resistance in Arabidopsis by biocontrol bacteria. Mol. Plant-Microbe Interact. 10:716-724.

Wandersman, C., and Letoffe, S. 1993. Involvement of lipopolysaccharide in the secretion of Escherichia coli $\alpha$-haemolysin and Erwinia chrysanthemi proteases. Mol. Microbiol. 7:141-150.

Wei, C. F., Deng, W. L., and Huang, H. C. 2005. A chaperone-like HrpG protein acts as a suppressor of $\mathrm{HrpV}$ in regulation of the Pseudomonas syringae pv. syringae type III secretion system. Mol. Microbiol. 57:520-536.

West, N. P., Sansonetti, P., Mounier, J., Exley, R. M., Parsot, C., Guadagnini, S., Prevost, M. C., Prochnicka-Chalufour, A., Delepierre, M., Tanguy, M., and Tang, C. M. 2005. Optimization of virulence functions through glucosylation of Shigella LPS. Science 307:13131317.

Zeidler, D., Zahringer, U., Gerber, I., Dubery, I., Hartung, T., Bors, W., Hutzler, P., and Durner, J. 2004. Innate immunity in Arabidopsis thaliana: Lipopolysaccharides activate nitric oxide synthase (NOS) and induce defense genes. Proc. Natl. Acad. Sci. U.S.A. 101:15811-15816.

\section{AUTHOR-RECOMMENDED INTERNET RESOURCE}

National Center for Biotechnology Information BLAST server: www.ncbi.nlm.nih.gov/BLAST 